\title{
« Private investment with social benefits under uncertainty: The dark side of public financing »
}

\author{
Auteurs \\ Giuseppe Attanasi, Kene Boun My, Marco Buso, Anne Stenger \\ Document de Travail n² $2016-12$
}

October 2017

Faculté des sciences économiques et de gestion

Pôle européen de gestion et d'économie (PEGE) 61 avenue de la Forêt Noire

F-67085 Strasbourg Cedex

Secrétariat du BETA

Géraldine Del Fabbro Tél. : (33) 0368852069 Fax : (33) 0368852070 g.delfabbro @unistra.fr www.beta-umr7522.fr 


\title{
Private investment with social benefits under uncertainty: The dark side of public financing
}

\author{
Giuseppe Attanasi ${ }^{*}, \quad$ Kene Boun $\mathrm{My}^{* *}, \quad$ Marco Buso ${ }^{* * *}, \quad$ Anne Stenger $^{* * * *}$
}

October 1,2017

\section{PRELIMINARY DRAFT}

\begin{abstract}
We develop a game-theoretic model of private-public contribution to a long-term project, with sequential actions and moral hazard. The private agent is in charge of both financial contribution and management effort, the two actions implying private costs, and uncertain ex-post private and social benefits. The public agent decides the amount of financial contribution knowing that the size and the probability to attain a higher surplus ex-post positively depend on the private agent's effort. We consider different public funding scenarios: benefit-sharing vs. cost-sharing, crossed with ex-ante vs. ex-post government intervention.

We test our theoretical predictions through an experiment. On the one hand, the experiment confirms the main result of the model: cost-sharing public intervention is more effective than benefitsharing in boosting private financial contribution to the project. On the other hand, we find that when public contribution comes after private contribution (ex-post government intervention), both public funding scenarios reinforce private contribution but they 'crowd out' private management effort.

These results have policy implications for strategic investments with long-term social consequences: in deciding the optimal timing and method of contribution, the government should consider not only direct short-term effects of its intervention, but also indirect effects on long-term agents' management efforts.
\end{abstract}

Keywords: Privately-provided adaptation public good, Public-private contribution, Moral hazard, Uncertain benefits, Benefit sharing, Cost sharing, Crowding out, Laboratory experiment.

JEL classification: C72, C91, D86, H4, H5.

\footnotetext{
* giuseppe.attanasi@,univ-lille1.fr; LEM-CNRS (Lille Economics Management, UMR 9221), University of Lille 1, Cité Scientifique, 59655 Villeneuve d'Ascq Cedex FRANCE. We are grateful to Stefania Innocenti, Nicolas Lampach and participants at the IMEBESS 2016 meeting, the IAERE 2016 conference, the 2015 European meetings of the Economic Science Association (ESA), the 2015 ASFEE conference and the "Workshop on the Economics and Management of Public Private Partnerships: Will Public Private Partnerships Improve Our Future?” (Venice, 2015) for their valuable comments and suggestions on different versions of this paper. Any remaining errors are the authors' responsibility. A. Stenger acknowledges financial support by ANR "ForWind" 012-AGRO 0007.

** bounmy@unistra.fr; Bureau d'Economie Théorique et Appliqué, UMR 7522 CNRS Université de Strasbourg.

*** marco.buso@,unipd.it; Department of Economics and Management "Marco Fanno", University of Padova.

**** anne.stenger@nancy.inra.fr; LEF (Laboratoire d'Economie Forestiére) UMR 356, INRA, AgroParisTech; BETA, Bureau d'Economie Théorique et Appliqué, UMR 7522 CNRS Université de Strasbourg.
} 


\section{Introduction}

In all developed and developing countries one pressing challenge is to take the path of smart, sustainable and inclusive growth allowing for the creation of jobs and prosperity within a global framework characterized by mayor technological, climatic and social changes.

An answer to these challenges stays on large-scale and long-term investment that (i) allows for the formation of long-lived capital, covering tangible assets (such as energy, transport and communication infrastructures, industrial and service facilities, housing and climate change and eco-innovation technologies) and intangible assets (such as education and research and development) (ii) boosts innovation and competitiveness (EU Green Paper 2013). Many of these investments have wider public benefits since they generate greater returns for society as a whole by supporting essential services and improving living standards.

Developed countries already started to allocate large portion of their budgets to pursue these longterm objectives. Recently EU launched the Horizon 2020 program that, inter alia, aims at financing projects related to: secure, clean and efficient energy; climate action, resource efficiency and raw materials providing; smart, green and integrated transport; research infrastructures; strategic investments in key technologies; food security, sustainable agriculture and forestry, marine, maritime and inland water research and the bio-economy (Horizon 2020 website).

Such investment is not always able to attract private investors due to the high level of uncertainty that characterizes private outcomes. Moreover, these projects imply large social benefit that are not considered by private agents. On the one hand, public funding can correct these market failures, giving private agents incentives to consider positive externalities for the society. On the other hand, public funding is primarily short-term and focuses on early stages of the investment (Borgstrom et al., 2016). This is because the high level of future uncertainty make formal and informal contracts technically unfeasible. ${ }^{1}$ Thus, the presence of incomplete contracting limits the possibility of regulation and control on ex-post outcomes. Large investment in innovation, climate change adaptation or green energy research projects do not always imply higher capacity of the society to innovate, react to climate changes or produce clean energy. Looking at past experiences, public subsidies have been found to be effective in enhancing the initial level of total investment; however in most cases, long-term effects are negligible and they depend on external factors (Cerqua and Pellegrini, 2014; de Blasio et al., 2011; Lerner, 1999).

Taking the particular issue of climate change, many natural disasters provoking economic damages are consequences of climate change, i.e., drought, insect plagues and windstorms. An important feature that characterizes these natural disasters is that consequences can be costly with big losses but more often individuals still seem to neglect these risks in the long term. This latter attitude consists in a biased perception and thus some underinvestment in adaptation effort. In fact, even if adaptation efforts do benefit first to the agents who invest in adaptation, due to high uncertain effects of climate change in the future, 'maladaptation' exist: disturbances in nature being higher with inadequate infrastructures, so 'autonomous adaptation' leaving adaptation only to individuals is not an issue; adaptation to climate change is a challenge for policy-markets as adaptation benefits to a larger society. In this view of 'privately-provided adaptation public goods' (Bergstrom et al., 1986), innovative public-private partnerships are needed (Tompkins and Eakin, 2012).

In our paper we want to deal with this issue by empirically testing how the public contribution on the level of investment can impact the management and, as a consequence, the final realization of the project in a context characterized by neither positive nor negative production externalities between investment and management (neutral context). In order to answer our research question we develop a game-theoretic model of private-public contribution to a long-term project, with sequential actions and moral hazard. The private agent is in charge of both financial contribution and management effort,

\footnotetext{
${ }^{1}$ It is difficult to contractually define ex-ante all contingencies that can occur later on, and if it is still possible, the cost of writing or enforcing the contract is normally excessively high (Tirole, 1999).
} 
the two actions implying private costs, and uncertain ex-post private and social benefits. The public agent decides the amount of financial contribution knowing that the size and the probability to attain a higher surplus ex-post positively depend on the private agent's effort. We consider different public funding scenarios: benefit-sharing vs. cost-sharing, crossed with ex-ante vs. ex-post government intervention.

We test our theoretical predictions through a laboratory experiment. During the experiment, the above-described game of (public-private) financial contribution and (private) management of the 'adaptation public good' is played repatedly a finite number of times, by relying on Andreoni's (1988) strategic explanation of excessive giving to a public good in a finetely-repeated setting.

We finally compare our empirical findings with the results provided by the theoretical analysis. As a further development we test different timing of the government intervention to empirically study whether final project outcomes are related with the moment that information on public contribution is made available to the private agent.

We find that, despite the fact that public intervention is limited at the early stage of the project, and theoretically it has an effect only on short-term outcomes, private agent's behavior is affected both in the short and the long run. Precisely, the public intervention effect on short-term outcomes is positive and close to what predicted by the theory, but we discovered a further negative "behavioral additionality" effect on the long-term private effort. This negative impact is especially observed when the public contribution is particularly low, and it is defined "ex-interim", e.g., after the investment level is chosen. In line with Bergstrom et al. (1986), we interpret this result as a form of crowding out of government (short-term) contribution to the public good over its (long-term) private management.

In accordance with Bowles and Reyes (2009), our results provide evidence that economic incentives provided through public policies may have unintended effects as they affect both agents' preferences and beliefs. As further evidence of this, in our experiment individuals seems to exhibit a concern for negative reciprocity, as they are willing to harm themseleves to punish unfair behavior by their partners (Dufwenberg and Kirchsteiger, 2004; Charness and Rabin, 2002). ${ }^{2}$

The paper is structured as follows. In Section 2, we briefly review the related literature. Section 3 presents the model. Section 4 describes the experimental design. In Section 5, we report and discuss empirical findings. Section 6 concludes.

\section{Literature review}

Our paper is linked to three big strands in the literature. First, there is one strand on public funding for innovation and strategic investment; second, an illustration in the area of adaptation to climate change is given, particularly focusing on the characteristics of adaptation as a public good; then a third big strand of our ur work is linked to the experimental literature studying the role of incentives and reciprocity in sequential games.

Developed countries are spending significant amounts of public money on programs that aim at stimulating innovation activities (Clausen, 2009), especially in strategic sectors (i.e., forest, transport, health). In these domains governments intervene to provide incentives for strategic innovation investment, nature conservation projects, ecological restoration policies or health (pharmaceutical) products development (Borgstrom et al., 2016; Jeffrey et al., 2014; Olsen and Fearnley, 2014; Widdus, 2001).

Public intervention is explained by the presence of market failures. In fact, private firms will underinvest in these innovative and strategic activities as they are not able to appropriate all the benefits arising from their investment (Clausen, 2009; Clarysse et al., 2009; Gonzalez et al., 2005; Luukkonen, 2000). When social returns of these activities are relevant, public bodies can intervene

\footnotetext{
${ }^{2}$ In our model an unfair behavior by the public partner cosists on a level of contribution that is lower with respect to the efficient level.
} 
through different incentive schemes such as: prize, intellectual property (IP), procurement, grants (Gallini and Scotchmer, 2002). Most of these tools have a strong incentive power, but they require the ability for the government to evaluate ex-post outcomes. Because of the high level of uncertainty that characterizes innovation activities, the most powerful incentive mechanisms cannot be applied, and then governments are obliged to intervene though direct grants or subsidies during the early stages of the projects (Jaumotte and Pain, 2005).

In such a context, it is interesting to understand whether this support has an effect only on the short term, or it affects also the long-term behavior of the private investor. A particular strand of literature states that public funds has more than a direct effect on the level of investment, but it can completely change the way investors behave during and or after the project implementation, both for the better or for the worse. This idea is summarized by the concept of "behavioral additionality" that can explain permanent effect in the attitude of the investor to innovate (Clarysse et al., 2009; Falk, 2007; Heijs, 2003; Luukkonen, 2000). ${ }^{3}$ Looking at the literature, there are some empirical evidences showing that public incentives can have more that a direct effect. On the one hand, they can provide additional positive impacts on the ability of the investor to learn the innovation process, and open new possibilities for exchanges through informal contracts (Falk, 2007; Luukkonen, 2000). On the other hand, public intervention can have negative effects on private behaviors. For instance, the public support can create a crowing out effect on private innovation investment, or, in the case of intellectual property, it can paradoxically lead to fewer useful products for improving human health (Heller and Eisenberg, 1998). ${ }^{4}$

However, there is in general little evidence of effectiveness of public support on the long term; then, it is difficult to assess how much behavioral additionality are relevant. There are few papers that focus on long-term impacts of public subsidies, and find substantially no effect on durable outcomes such as workers' productivity or the capacity to innovate (Cerqua and Pellegrini, 2014; de Blasio et al., 2011). Very linked to our paper is the analysis of Lerner (1999) that looks at the long-run impact of the Small Business Innovation Research (SBIR) program in the USA. The SBIR program is a policy to provide early-stage financing to firms, particularly high-technology companies. Despite short-term effects of the program are positive and highly significant (Audretsch et al., 2002), authors find that the positive impact in the long-run is strictly related to external factors, such as the intensity of venture capital activity in neighbouring areas. Otherwise, in the absence of such external factors, the program was no effective in the long run to enhance firms' productivity or growth.

Finally, the effectiveness of the government support can depend on the timing of the intervention (Georghiou, 1998), or on the private investors' expectations about the level of contribution (Gonzalez et al., 2005). These issues are discussed in the literature, but there is a lack of empirical evidence. Behavioral responses to public intervention are in general extremely difficult to be assessed from an empirical point of view because of the lack of reliable data on ex-post long-term outcomes, and the difficulty of isolating and measuring behavioral responses of private investors. A possible solution to this problem comes from randomized experiments that allow researchers to detect behaviors of agents under a controlled environment. In this paper we use an experimental approach together with a theoretical framework that allows us to interpret our results and especially differences with theoretical predictions.

When looking at adaptation to climate change as a public good, all these previous issues around innovative actions and (under)investment, uncertainty in the outcomes, the timing of the adaptive actions and the long-term impacts on climate, the coordination of the different agents' several efforts and the incentives to motivate or the institutional mechanisms to encourage private provision are relevant.

If mitigation is more seen as a public good whereas adaptation as a private one, this last set of

\footnotetext{
${ }^{3}$ These behavioral additionality effects are relevant especially when public support lacks incentive power (Heijs, 2003).

${ }^{4}$ The idea is that upstream patents that interfere with downstream product developments make agreement with different actors more difficult and, as a consequence, less successful.
} 
adaptative actions can encompass the global society who invests in new technologies (Hasson et al, 2010). The characteristics of public good for adaptation relies as well on the fact that public agencies, governments or institutions can take actions at some larger scales than individuals (Adger et al , 2005). If adaptation has some immediate and local benefits, efficient adaptation needs to overcome some positive externalities of investments or inadequate information on climate change (Stern, 2007) that can hinder some long-term investments for private partners. Not only adaptation requires that all sectors take their responsibility but its efficiency strongly depends as well on agents' coordination at national and international levels.

Moving to the experimental literature, there are not so many papers studying the role of incentives in a multi-period environment. A prominent contribution is provided by Huck et al. (2011) that propose the first experimental test of (Lazear, 1979)' model of deferred compensation. By using a simple three-period model, the authors demonstrate that when short-term monitoring of worker productivity is either costly or not possible, then the optimal structure of wage under commitment should imply deferred compensation in order to increase worker effort. A further contribution on this strand of literature is provided by Nieken and Schmitz (2012). In the paper they test a more general framework investigated by Ohlendorf and Schmitz (2012); precisely, they analyze the role of longterm contracts with and without memory in a repeated hidden action framework. Conforming with the theory, they found that - principal make much larger profits and the agent exerted more effort on the first period when a contract with memory is chosen - the second-period effort in case of contract with memory was significantly higher following a first-period success than a first-period failure. Finally, on the base of a theoretical framework based on Hart (2003), Hoppe et al. (2013) test a model related to public-private partnerships (PPPs) through an experiment in the laboratory. In fact, they compare the contracting out of two sequential tasks to a single contractor (bundling) with the assignment of each activity to a different agent (unbundling). The experiment confirms the theoretical evidence suggesting the use of PPPs to provide stronger incentives to make cost-reducing investments.

Similarly to previous works, we develop and test a model with sequential activities and moral hazard. However, differently from the literature, we do not have a direct link between the first and the second stage of the model. Moreover, we follow an incomplete contract approach since uncertainty makes long-term contracts based on future verifiable outcomes too costly or impossible to be written. Thus, we test whether incentives on the first-period stage affect agents' behavior during the second-stage activity in the absence of a production externality and we detect a new behavioral result. Our experiment can partially explain why public funding limited to early stages of the projects have no or negligible impact on log-term outcomes. Moreover, we state that: when short-term public support is not adequate (in the form of the level and timing of contribution) or it does not respond to private expectations, the effect on the long-term probability to attain higher social surpluses can be negative.

As we control for the presence of risk and inequity aversions, this last result demonstrates that subjects are also motivated by reciprocity, meaning that their behavior also depends on how fairly people that interact with them are behaving. This aspect is studied by the experimental literature that focus on the role of social preferences. Charness and Rabin (2002) test the role of reciprocity though the use of response games and demonstrate that individuals are willing to sacrifice to allocate the fair share toward somebody that have followed a fair behavior, while they significantly increased their Pareto-damaging behavior following unfair actions taken by their partners. Dufwenberg and Kirchsteiger (2004) dvelop a theory of sequential reciprocity and through several experimental examples show that intentions are crucial in order to exlain reciprocity, and intentions depend on the beliefs of players. Finally, an interesting application of this concept on public finance is provided by Andreoni et al. (1998) that show as the amount of tax evasion is affected by the perceived fairness of the tax system. 


\section{The model}

Two players, the private agent and the public regulator, are interested in realizing a long-term project with uncertain outcomes (e.g., an adaptation investment to face climate change shocks). More precisely, the project consists on two stages: the investment stage and the management stage.

In the investment stage, the private agent chooses an amount of investment $I$ incurring a monetary cost equal to $\frac{I^{2}}{2 p}$, with $p>0 .{ }^{5}$ We consider the level of investment essentially as a quantitative and not qualitative measure (i.e., the total size of the project).

In the management stage, the private agent is in charge of the management activity: he manages the investment knowing that future outcomes positively depend on the effort $e \geq 0$ exherted during the management stage. More precisely, marginal private returns $R$ are high, $R^{h}$, with probability $\frac{e}{k}$, and low, $R^{l}<R^{h}$, with probability $\left(1-\frac{e}{k}\right)$, with $k>0$ representing the highest possible management effort the agent can exhert (i.e., $k \geq e$ ).

Marginal social returns $S$ are perfectly correlated with private ones, hence they correspond to $S^{h}$ with probability $\frac{e}{k}$, and to $S^{l}<S^{h}$ with probability $\left(1-\frac{e}{k}\right)$. The management activity implies nonmonetary marginal costs to the private agent equal to $\frac{e^{2}}{2 k q}$, with $q>0 .^{6}$

The public regulator cannot verify neither the agent's effort (moral hazard), nor the final outcomes of the project. As a consequence, there is not the possibility to write contracts on the base of contingent outcomes. Here we rely on the large literature on incomplete contracts (see, e.g., Hart 1988): incomplete contracting is quite typical in contexts where future uncertainty may result in excessive transaction costs of writing complete contracts.

Furthermore, we assume that the higher the initial size of the project $(I)$, the stronger the expected returns and the management costs. Thus, the impact of $I$ on the management stage is symmetric between benefits and costs.

The time-line of the investment is reported in the following graph:

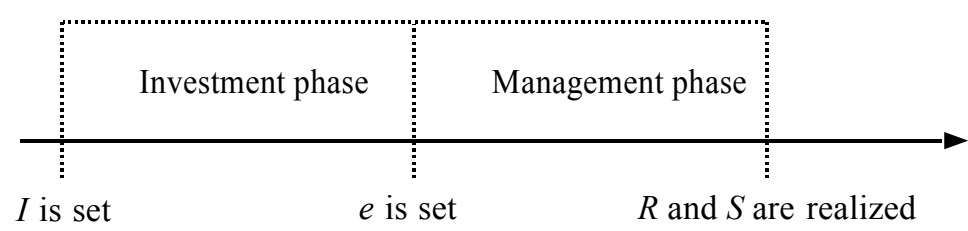

Starting from this setting, our model aims at explaining how governance tasks and responsibilities should be shared between public and private actors in a context characterized by endogenous risks, asymmetry of objectives and public finance distortions. In fact, the public regulator is interested in the investment implications in terms of social welfare, while the private agent aims at enhancing private returns from the two investments. Moreover, whenever the public regulator sustains monetary costs, the shadow cost of public funds $(\lambda)$ is considered as a way to capture the distortion imposed to taxpayers for financing the investment.

\footnotetext{
${ }^{5}$ Investment costs are assumed as quadratic, the analysis can be generalized by considering general cost functions $c(I)$ that satisfy the following properties: $c^{\prime}(I)>0, c^{\prime \prime}(I) \geq 0$.

${ }^{6}$ Management costs are assumed as quadratic, the analysis can be generalized by considering general cost functions $\psi(e)$ that satisfy the following properties: $\psi^{\prime}(e)>0, \psi^{\prime \prime}(e) \geq 0$.

7 As we stated in the Introduction, we explicitly make this assumption in order to study the impact of the government intervention on the private behavior during the management stage in the absence of explicit externalities.
} 


\subsection{First-Best and Private scenarios}

At the first best, it is assumed a context of symmetric information. We find that both the optimal management effort and the optimal initial investment are positively correlated with the level of private revenues and social surpluses:

$$
\begin{aligned}
e^{f b} & =\frac{q(\Delta R+\Delta S)}{2} \\
I^{f b} & =\frac{p\left[q(\Delta R+\Delta S)^{2}+4 k R^{l}+4 k S^{l}\right]}{8 k}
\end{aligned}
$$

Proof. See Appendix A.

Under the private (benchmark) scenario, the private agent is fully in charge of financing and implementing the investment. In this case, there is no strategic interaction: the private agent is the only active player in the game, making two subsequent choices: $e$ and $I$. Thus, it is two-stage individual decision-making problem.

Solving the problem backwards, the player chooses the optimal level of management effort and how much he wants to invest in the long-term project. Optimal results are as follows:

$$
\begin{aligned}
e^{p r} & =\frac{q \Delta R}{2} \\
I^{f b} & =\frac{p\left[q \Delta R^{2}+4 k R^{l}\right]}{8 k}
\end{aligned}
$$

Proof. See Appendix B.

Notice that optimal values under the private scenario do not include social surpluses and are lower than first-best outcomes $\left(e^{p r}<e^{f b}, I^{p r}<I^{f b}\right)$.

\subsection{Public-Private scenarios}

Looking at the investment result under the private scenario, it is evident how the social surplus is not taken into account; as a consequence, the optimal choice is lower than the first-best outcome. Assuming that revenues and social surpluses cannot be verified ex-post (incomplete contract), the government can only affect final decisions either by increasing the private benefit or by lowering the monetary cost from a higher investment. To reach these goals, the government intervention should be set as follows:

- In the first case, the government can grant the private owner a transfer $(C)$ that increases his marginal benefit from the investment: Benefit-sharing scenario;

- In the second case, the government sustains a fraction of the investment cost $(T)$ : Cost-sharing scenario.

In both the first and the second case, the optimal investment is decided by the private agent, while the transfer $C$ or the fraction $T$ are set ex-ante by the government.

We introduce the first case to analyze the standard method of government intervention on real world situations. In fact, in most cases, the public regulator sets a transfer that linearly increases with the level of total investment (e.g. incentives to insurance protection, incentives to innovation etc.). Then, we also consider a second situation when the government decides to pay part of the investment 
costs. This option is rarely chosen either because information on investment costs are not publicly available, or because of the additional expenses for the government to assess investment costs.

\subsubsection{Benefit-sharing scenario}

Starting from this case, the public regulator intervenes in the decision making process trying to influence the realization and implementation of the investment. Under a benefit-sharing scenario, the linear transfer is set by the public regulator before the decision of the investment level. Thereafter, after the financing phase, the private agent is in charge of managing the investment. The following graph summarizes the time of the investment implementation:

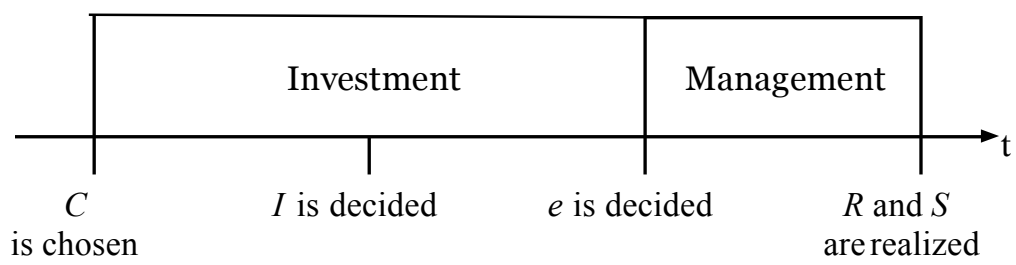

The problem is solved backwards to derive the values of effort, investment and transfer at the equilibrium. Optimal outcomes are as follows:

$$
\begin{aligned}
e^{b s} & =\frac{q \Delta R}{2} \\
C^{b s} & =\max \left\{\frac{q \Delta R \Delta S+2 k S^{l}}{4(1+\lambda) k}-\frac{q \Delta R^{2}+4 k R^{l}}{8 k}, 0\right\} \\
I^{b s} & =\max \left\{I^{p r}, \frac{p\left[q \Delta R^{2}+4 k R^{l}\right]}{16 k}+\frac{p\left[q \Delta R \Delta S+2 k S^{l}\right]}{8(1+\lambda) k}\right\}
\end{aligned}
$$

Proof. See Appendix C.

While the social surplus is not included in the management effort, it is considered in the investment level that is higher with respect to the benchmark scenario when the social surplus is sufficiently large: $E[S]=\frac{e^{b s}}{k} S^{h}+\left(1-\frac{e^{b s}}{k}\right) S^{l}>\left(\frac{e^{b s}}{2 k}\left(R^{h}-R^{l}\right)+R^{l}\right)(1+\lambda)$. However, the value of the investment at the optimum is still lower than the first-best (eq. 1) due to the presence of incomplete contracts on the management stage and public finance distortions $(\lambda)$.

\subsubsection{Cost-sharing scenario}

Differently from the previous case, under this scenario the public regulator pays part of the investment costs by deciding ex-ante a cost-sharing coefficient $(T)$. The following graph summarizes the time of the investment implementation:

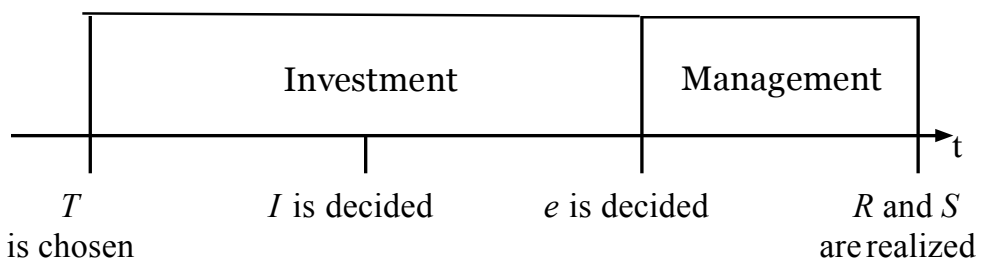

The maximization problem is solved backwards. Optimal outcomes are as follows: 


$$
\begin{aligned}
e^{c S} & =\frac{q \Delta R}{2} \\
T^{c S} & =\max \left\{\frac{4\left(q \Delta R \Delta S+2 k S^{l}\right)-(1+\lambda)\left(q \Delta R^{2}+4 k R^{l}\right)}{4\left(q \Delta R \Delta S+2 k S^{l}\right)+(1+\lambda)\left(q \Delta R^{2}+4 k R^{l}\right)}, 0\right\} \\
I^{C S} & =\max \left\{I^{p r}, \frac{p\left[q \Delta R^{2}+4 k R^{l}\right]}{16 k}+\frac{p\left[q \Delta R \Delta S+2 k S^{l}\right]}{4(1+\lambda) k}\right\}
\end{aligned}
$$

\section{Proof. See Appendix D.}

While there are still no differences related to the optimal effort, the level of investment under this scenario (eq. Errore. L'origine riferimento non è stata trovata.) is higher with respect to the benchmark case if the expected surplus is sufficiently large: $E[S]=>\left(\frac{e^{c S}}{2 k}\left(R^{h}-R^{l}\right)+R^{l}\right) \frac{(1+\lambda)}{2}$. Moreover, the optimal investment is always higher than the result coming from the benefit-sharing maximization (eq. Errore. L'origine riferimento non è stata trovata.); this final statements leads to the following propositions:

Proposition 1 The government participation on the decision making process results in a different level of optimal investment depending on the intervention method: the cost-sharing regime (government holds part of the monetary cost) is more effective in terms of final investment than a benefit-sharing rule (linear transfer increasing total benefit).

Proposition 2 The government participation on the decision making process results in an equal level of management effort independently on the public intervention $\left(e^{c s}=e^{b s}=e^{p r}\right)$. This result comes from the impossibility for the government to contract the management stage.

\subsection{Developments and parametrization of the model}

As a development of the model, we consider different timing for the government intervention. In fact, real world situations show as the level of public contribution on the investment stage is not always specified at the beginning, but either after the investment stage is finished, or during the investment process. This government behavior is largely explained by the presence of budget constraints that make the availability of more or less funds dependent on the approval of the financial statement at the end of the year. From a theoretical point of view, there are not government incentives to intervene after the investment decision is taken. However, given that this development is interesting from an empirical point of view, in our experiment we consider the possibility for the government to intervene after the private investment decision, considering both the benefit-sharing and the cost-sharing governance.

To apply our experimental design we assign some specific parameters to the model, precisely: $R^{h}$ and $S^{h}$ are equal to $5 ; R^{l}$ and $S^{l}$ are equal to $1 ; \lambda=0 ; I$ can be any integer between 0 and 8 ; $e$ can be equal to 2,4 or $6 ; C$ can be $0,0.5,1,1.5$ or $2 ; T$ can be $0,0.2,0.5$ or $0.8 ; k=8 ; p=4 ; q=2$. With these parameters the model expectations are as follows:

- $I=4, e=4$ and $C=0.5$ in the case of private regime or when the government contribution is defined after the investment level (private, ex-post benefit-sharing and ex-post cost-sharing);

- $I=5$ and $e=4$ in the case of benefit-sharing governance with ex-ante government intervention (ex-ante benefit-sharing);

- $I=8, e=4$ and $T=0.5$ in the case of cost-sharing governance with ex-ante government intervention (ex-ante cost-sharing). 


\section{Experimental Design}

Starting from these theoretical predictions, we develop an experimental design made of five treatments:

1. Private (Benchmark Scenario): the private agent chooses first the level of investment $\left(I^{p r}\right)$, then the optimal effort $\left(e^{p r}\right)$;

2. Ex-ante Benefit-Sharing (ex-ante BS): the government decides the optimal marginal transfer $(C)$, then the private agent sequentially chooses the levels of investment $(I b s, b)$ and effort $\left(e^{b s, b)}\right.$;

3. Ex-ante Cost-Sharing (ex-ante CS): the government decides the optimal cost-sharing parameter $T)$, then the private agent sequentially chooses the levels of investment $(I c s, b)$ and effort $\left(e^{c s, b}\right)$.

4. Ex-post Benefit-Sharing (ex-post BS): the private agent chooses the level of investment $(I b s, a)$, then the government decides the optimal marginal transfer $(C)$, finally the private agent chooses the level of effort $\left(e^{b s, a}\right)$;

5. Ex-post Cost-Sharing (ex-post CS): the private agent chooses the level of investment (Ics,a), then the government decides the optimal cost-sharing parameter $(T)$, finally the private agent chooses the level of effort $\left(e^{c s, b}\right)$.

Figure 1 reports the time-lines of the five different treatments as they are shown to participants.

[Figure 1 here]

\subsection{Experimental Treatments}

The whole game experiment is made of three parts. In the first two parts we test the degree of risk aversion and inequity aversion of each individual. Then, in the third part we test our model.

For the "advantageous inequity aversion game" we use a modified version of the dictator game proposed by Blanco et al. (2011) in order to elicit the degree of inequity aversion of participants. We model inequity aversion in accordance with the definition of Fehr and Schmidt (1999) that considers individuals inequity averse if they dislike outcomes that are perceived as inequitable. In the game each subject is assigned to another player that is in the room. Then, each participant has to select between two choices in a multiple-line list. More precisely, the left choice gives $10 €$ to player A and $0 €$ to player B for all lines, while the right choice gives the same amount to the two players, from a minimum of 1 (line 1) to a maximum of 10 (line 10). Each subject has to play knowing that his decision is relevant only if he will be finally selected as player A. Moreover, once the participant selects for a certain line the right choice, then the computer will automatically assign the right choice for all the following lines (assumption of rationality). Finally, at the end of the experiment, the computer will randomly decide who is player $\mathrm{A}$ and $\mathrm{B}$ for each couple and it will draw one of the ten lines. If you are selected as player A, final payoffs of the couple depend on your own choice for the drawn line, while if you are selected as player B, final payoffs will depend on your partner's choice.

For the second game we use the method adopted by Chakravarty and Roy (2009) in order to elicit the degree of risk aversion of participants. In the game each participant has to select between two choices in a multiple price list similar to the one proposed by Holt and Laury (2002). More precisely, the left choice gives the player $10 €$ with probability $1 / 2$ and $0 €$ with probability $1 / 2$, while the right choice gives the player A certain amount that varies from 1 (line 1) to 10 (line 10). We still assume rational choices, then once the player switches from the left to the right option, then the computer will automatically assign the right choice for all the following lines. Finally, at the end of the experiment, the computer will draw whether you win or loose in the case of the right option, and it 
will randomly select one of the ten lines. If for the drawn line you selected the right optio,n you will receive for sure the line correspondent amount; however, if you selected the left option you will receive $10 €$ or $0 €$ depending on the result of the random lottery. Instructions for the general framework and the first two rounds are given at the beginning of the each game (see Appendix E), however final draws and payments are made at the end of the experiment, i.e, after the third game.

In the last game a subject is randomly selected as a player $\mathrm{X}$ or $\mathrm{Y}$ and he keeps that role for the 12 periods of the game. There are a total of 24 participants, divided into 2 groups of 12 participants. At the beginning of each period, 12 pairs are made of two subjects randomly chosen from the 24 participants. Each pair consists of a X and a Y player, where an X player are in touch with a player $\mathrm{Y}$ and viceversa. Each player does not know the identity of his pair, and to facilitate the understanding of the experiment we always call $\mathrm{X}$ the player that makes the first choice. Furthermore, the pair is randomly chosen before each new period and it's impossible to meet the same participant twice during the 10 periods of the game (perfect stranger). The task of each subject is different depending on which is the selected scenario. In each session we test just one governance, thus we perform two independent sessions for each governance (10 in total). In the next paragraphs we will describe more in details the functioning of the different treatments. In Appendix $\mathrm{F}$ we report the instruction for one of the five treatment (ex-ante cost-sharing).

\subsubsection{Private scenario}

In the private game, the player $X$ corresponds to the private owner, while the player $Y$ is the public regulator. Each time the player $X$ must sequentially take two types of decisions: an investment level $I$ and the number of white balls $B$ to purchase in a box consisting of 8 white and black colored balls ( $B$ corresponds in the model on the level of effort $e$ ). The investment $I$ can be any integer between 0 and 8 and it generates for the player $Y$ an investment cost equal to $\frac{I^{2}}{4}$, while it provides an identical income for players $X$ and $Y$ that depends on which is the color of the ball that will be drawn $\left(5^{*} I\right.$ if it is a white ball, $1^{*} I$ if it is a black ball). The number of white balls can assume four possible values: $0,2,4$ or 6 . Depending on the number of white balls bought, the urn is composed of either 0 white ball and 8 black balls, or 2 white balls and 6 black balls, or 4 white balls and 4 black balls 4 , or 6 white balls and 2 black balls. The probability of drawing a white ball in the box is equal to $\frac{B}{8}$. The cost of purchasing a number of white balls $B$ for the player $Y$ is: $\frac{B^{2} I}{16}$. The player $Y$ can simulate $X^{\prime}$ decisions having a table of the final payoffs, however he has a passive role under this scenario because he cannot affect decisions of player $X$.

\subsubsection{Benefit-sharing scenario}

In the BS scenario (ex-ante), the player $X$ corresponds to the public regulator (private owner for the ex-post BS), while the player $Y$ is the private owner (public regulator for the ex-post BS). Differently from the private regime, in this case the public regulator participates in the decision making process by deciding the benefit-sharing coefficient $C$. Each time the public regulator must decide whether he wants to share or not part of his income with the private agent choosing the value of the coefficient $C$. The coefficient can take five possible values: $0,0.5,1,1.5$ or 2 , and the amount transferred to the private agent is equal to $C^{*} I$. Thus, in this case the lord income of the two players is respectively equal to: $(5+C) * I$ if it is a white ball, $(1+C) * I$ if it is a black ball for the player $Y$; and $(5-C) * I$ if it is a white ball, $(1-C)^{*} I$ if it is a black ball for the player $X$. As in the previous scenario, at the end of each round players can observe their results. According to this framework we test two different treatments:

- in the ex-ante BS the public actor $X$ sets $C$ before the choice of $I$;

- in the ex-post BS the public actor $Y$ sets $C$ after the choice of $I$; 


\subsubsection{Cost-sharing scenario}

In the CS scenario (ex-ante), the player $X$ corresponds to the public regulator (private owner for the ex-post CS), while the player $Y$ is the private owner (public regulator for the ex-post CS). Differently from the private regime, in this case the public regulator participates in the decision making process by deciding the cost-sharing coefficient. Each time the public regulator must decide whether he wants to pay part of the investment costs of the private agent choosing the value of the coefficient $T$. The coefficient can take four possible values: $0,0.2,0.5,0.8$. Then, the investment cost paid by the private agent is equal to $(1-T) \frac{I^{2}}{4}$, while the fraction paid by the public regulator is equal to $T \frac{I^{2}}{4}$. As in the previous scenarios, at the end of each round players can observe their results. According to this framework we test two different treatments:

- in the ex-ante CS the public actor $X$ sets $T$ before the choice of $I$;

- in the ex-post CS the public actor $Y$ sets $T$ after the choice of $I$.

\subsection{Experimental Procedures}

The program of this experiment has been designed with the web platform EconPlay. The experiment was run on a computer network using 240 inexperienced students at the BETA Laboratory of Experimental Economics (LEES) at the University of Strasbourg. Ten sessions were organized, with 24 subjects per session. A total of 288 independent observations (couple observations) per treatment was collected. Subjects were randomly assigned to a computer terminal, which was physically isolated from other terminals. Communication, other than through the decisions made, was not allowed. The subjects were instructed about the rules of the game and the use of the computer program through written instructions, which were read aloud by an experimenter. Instructions for game 2 has been given only after game 1 was terminated, and similarly instructions for game 3 has been given only after game 2 was terminated.

Finally, each player before starting game 3 had to answer a questionnaire of 10 questions aiming at capturing the level of understanding of the instructions. Still related to the final game, it is important to point out that final payments were based on experimental currency units (ECU). More precisely, at each round the final payoff contributed to increase the total amount of points (ECU) gathered by each player. At the end of the 12 periods they received an amount of euro corresponding to the total sum of ECU divided by 10 .

\section{Data analysis}

In this section we report results for our 5 main treatments. In the first part we focus on the impact of public contribution on the level of investment; in the second part, taking into account the sequential pattern of our experiment, we describe the differential effect of our treatments in explaining the effort choice. Figures and Tables are reported at the end of the paper.

\subsection{Investment Stage: Private and Public Contribution}

We start by reporting the investment density and mean results for our 5 treatments. As described in the previous section, by implementing our experiment we obtained 288 observations for each treatment.

[Figure 2 here]

[Figure 3 here] 
Looking at Figures 2 and 3, we can have some first evidences confirming the predictions of our model. In fact, starting by the benchmark case, we can observe that the mean value as well as the highest frequency of answers are equal to 4, as predicted by our model. When we switch to cases with an active public participation (Public-Private scenarios), differences exist depending on the time-line of the public-private choices. On the one hand, when the public contribution is defined before the investment decision, empirical results are more or less confirming the theoretical predictions. In the case of benefit-sharing, the mean value is close to 5 as predicted by the model, while the highest frequencies of answers are between 4 and 6 . In the case of cost-sharing the mean value is almost 6 and the highest frequency is equal to 8 , as stated in the model. On the other hand, when the public contribution is defined after the investment decision, we observe that both in the case of benefitsharing and cost-sharing, differently from what is stated in the model, investment outcomes are significantly higher with respect to the private benchmark. However, in both scenarios results are significantly higher when the public contribution is defined ex-ante rather than ex-post. As a conclusion, we can say that the main model predictions are confirmed by our empirical results. Differences exist when the public contribution is defined after the investment choice (treatment 3 and 5). In such a situation, while according to the model there is no reason for the public actor to intervene, looking at the experimental outcomes we observe a public intervention that results in a higher final level of investment with respect to the private benchmark. The difference for what concerns agents' behavior can be explained by the sequential pattern of our experiment. In fact, the public actor is aware of the possibility for the private agent to punish the low level or the absence of government contribution by decreasing the final level of effort; we will return to this point on the next paragraph to comment results on the level of effort.

As a second step of our analysis we perform a parametrical regressions to test the effect of the government contribution on the level of investment by controlling for relevant covariates. Precisely, we control for: the degree of inequity and risk aversion of the private agent, some important personal features of the private agent (age, gender) and the level of understanding of the model dynamics. Taking into account these covariates, we can better describe whether the private choice related to the level of investment is explained by personal characteristics of the agent, his level of inequity or risk aversion, or the degree of public contribution. In particular we are interested in isolating this last effect. A detailed description of our control variables is provided in Table 1.

\section{[Table 1 here]}

To implement the analysis we match each private agent with the corresponding public partner and we treat each period as an independent observation; thus, as a robustness check, we cluster standard errors by period. We perform two main analyses: at first, we independently test each treatment; second, we look at differences among treatments. In the first case, we apply the following regression to describe for each treatment what explains the private investment decision:

$$
I_{i c p}=\alpha_{0}+\alpha_{1} p c c_{i c p}+\alpha_{2} X_{i}+\varepsilon_{i c p}
$$

where $i=$ individual, $c=$ couple, $p=$ period, and $p c=$ public contribution.

While for the benchmark case there is not the public contribution variable, in the case of treatment 2 and 3 it is given by the level of linear transfer $C$, and in the case of treatment 4 and 5 it is given by the cost-sharing parameter $T$. In the second case, we test the following regression that includes different treatments' data:

$$
I_{i c p t}=\alpha_{0}+\alpha_{1} D_{t}+\alpha_{2} X_{i}+\varepsilon_{i c p t}
$$

where $i=$ individual, $c=$ couple, $p=$ period, $t=$ treatment, and $D=$ dummies for treatment. 
In this regression we consider all data and we include dummies for treatment to look at differences on the investment level across scenarios. Results are reported in Table 2.

\section{[Table 2 here]}

Columns from 1 to 5 report results of the first regression using data related to respectively the following scenarios: private, ex-ante benefit-sharing, ex-post benefit-sharing, ex-ante cost-sharing, ex-post cost-sharing. Finally, in the last columns we test the second regression and we consider data related to respectively the following treatments: - column n. 6: private, ex-ante benefit-sharing, exante cost-sharing; - column n. 7: private, ex-post benefit-sharing, ex-post cost-sharing. We focus the discussion on our main explanatory variables. Looking at the second and the third columns we can see that the effect of $C$ (benefit-sharing parameter) on the investment is positive, but it is significant only when the public decision is taken before the private investment choice. In the fourth and the fifth columns we observe data related to the cost-sharing treatment. Similarly to before, the effect of $T$ on the investment is positive, but it is significant only when the public decision is taken before the investment choice. To summarize, when we test the first regression for each single treatment results confirm predictions of the model showing as the public contribution is effective essentially when decisions are taken before the private choices. In column 6 and 7 we look at the effects of the benefitsharing and the cost-sharing treatments relative to the benchmark case. In column 6 we focus on exante treatments and we observe that coefficients for the public-private governances are positive and significant meaning that the public participation is effective in enhancing the level of investment. The $c s-b s$ statistic looks at the difference between the cost-sharing and the benefit-sharing coefficients. it is positive and significant showing the greater effectiveness of the cost-sharing treatment to positively affect the level of investment. Finally, in the last column we focus on ex-post treatments. Coefficients of the public-private treatments are also positive and significant and even in this case the cost-sharing is more effective than the benefit-sharing treatment to increase the level of private investment. We test for the differences between ex-ante and ex-post coefficients and we found that both for what concerns the cost-sharing and the benefit-sharing dummies the effect is stronger when the public choice is taken ex-ante. To conclude, differently from what is predicted by the model a public contribution seems to be effective also when the public actor makes its choice after the private investment decision. However, conforming to the model, a public contribution is more effective in enhancing the level of investment when it is taken ex-ante and under a cost-sharing governance.

\subsection{Management Stage: Private Effort}

The level of effort should not be affected by the public intervention. Thus, applying the model parameters, the value of effort at the equilibrium should be equal to 4 independently of the treatment. Figures 4 and 5 report the effort mean and density per treatment.

[Figure 4 here]

[Figure 5 here]

On the one hand, looking at the density graph, we can observe that 4 is the choice that is most frequent in every treatment. On the other hand, looking at the average values, we can see that the public intervention leads to a lower level of effort. This statement is much more evident in the case of a benefit-sharing treatment or when the public participation is defined after the investment level. This result is counter intuitive, then we develop a parametrical analysis to better understand what drives 
this private behavior. In our experiment the private agent makes two sequential decisions: first he chooses the level of investment, then the level of effort. Thus, we apply for the empirical test a mediation analysis aiming at detecting whether the level of public contribution directly affect the level of effort, or only through the level of investment. Following the standard approach we implement: a regression for the outcome including the mediator among the independent variables, and a regression for the mediator (level of investment) to capture the indirect effect of the public contribution on the level of effort. To detect our causal mediation effects we apply the technique proposed by Imai et al. (2010) that allows for continuous and binary dependent variables and for a final estimation without reference to any specific statistical model. Similarly to the investment study we perform two main specifications. First, we test each treatment independently. Thus, apart from the private benchmark ${ }^{8}$, we use the level of investment as a mediator and we test the following regressions:

$$
\begin{gathered}
e_{i c p}=\beta_{0}+\beta_{1} p c_{i c p}+\beta_{2} X_{i}+\beta_{3} I_{i c p}+\varepsilon_{i c p} \\
I_{i c p}=\gamma_{0}+\gamma_{1} p c_{i c p}+\gamma_{2} X_{i}+\varepsilon_{i c p}
\end{gathered}
$$

where $i=$ individual, $c=$ couple, $p=$ period, and $p c=$ public contribution.

In the previous regressions $e_{i c p}$ is the level of effort, while $I_{i c p}$ is the level of investment, the remaining covariates are described in detailed in Table 1 in the appendix. Thanks to this approach we can detect both the direct effect of the public contribution on the level of effort $\left(\beta_{1}\right)$ and the indirect effect mediated through the level of investment $\left(\beta_{3} \gamma_{1}\right)$. Second, we test whether the level of effort varies among the different treatments. Precisely we test the following regressions:

$$
\begin{gathered}
e_{i c p t}=\beta_{0}+\beta_{1} D_{t}+\beta_{2} X_{i}+\beta_{3} I_{i c p t}+\varepsilon_{i c p t} \\
I_{i c p t}=\gamma_{0}+\gamma_{1} D_{t}+\gamma_{2} X_{i}+\varepsilon_{i c p t}
\end{gathered}
$$

where $i=$ individual, $c=$ couple, $p=$ period, $t=$ treatment, and $D=$ dummies for treatment.

In this regression the dependent and the mediator variables are as before, while among the covariates we include our treatment dummies. Results for the direct effect are reported in Table 3.

\section{[Table 3 here]}

Looking at the table we can observe that, excluding the "ex-ante CS", the public contribution positively and directly affect the level of effort both in the case of a benefit-sharing and a cost-sharing governance. On the one hand, this result is in contrast with the model that suggests no direct effect of the public contribution on the level of effort. On the other hand, from a behavioral point of view it seems plausible that private agents react to the public decision, essentially when the public choice is taken after the investment choice. Even more interesting are the last two columns that report the result of the second regression strategy. In column 6 we use data related to the following treatments: private, ex-ante benefit-sharing, ex-ante cost-sharing; while in the last column we use data related to the following treatments: private, ex-post benefit-sharing, ex-post cost-sharing. We observe that the effect of public participation on the level of effort is negative both considering a benefit-sharing and a cost-sharing governance. This result is much more stronger when we consider cases with an ex-post public participation (after the investment choice). This result is not in line with the model that suggests no effect of public contribution; then, what can explain this effect? Looking together at the different regressions we can observe that it exists a positive link between the level of effort and the level of public contribution, however treatments with a public contribution perform worse that the private

\footnotetext{
${ }^{8}$ In the private case we model an OLS regression with clustered standard error by period.
} 
benchmark in terms of effort. What can explain this dynamics is a sort of "penalty" effect applied by private actors. In fact, looking in details at data we can see that when the public contribution is equal to 0 or is lower than the optimal, then the private actor tends to penalize this behavior by lowering the optimal level of effort. This statement is even more clear looking at Figures 6 and 7 that graphically describe the relation between the level of public contribution and the level of private effort.

[Figure 6 here]

[Figure 7 here]

In all graphs we observe that when the level of public contribution is equal to zero or is lower than the optimal, then the private effort is between 2 and 3, and significantly lower than the optimal value 4. Finally, we are interested in understanding not just the direct effect, but also the indirect effect that is explained by the mediator (the level of investment). We report the decomposition of our effects in Table 4.

\section{[Table 4 here]}

We already discuss the direct effects that are almost always significant. However, the Average Causal Mediated Effect (ACME) are significant only for some treatments. On the one hand, when we test the impact of public contribution independently for each treatment (the first four tables), we detect a single significant effect that is related to the ex-ante cost-sharing treatment. In this case, while the total effect is positive and significant as in the remaining treatments, the decomposition shows that the impact is better explained by the mediated effect of the investment level rather than by the direct effect of the public participation. On the other hand, when we test the direct and indirect impact of the BS and CS dummies (the last four tables) with respect to the benchmark case (separately between ex-ante and ex-post treatments), we find a positive and significant ACME and a negative and significant direct effect. It means that the introduction of the public partner positively affect the level of effort through the incentive on the level of investment, while the direct impact is negative and significant. This analysis confirms the hypothesis of using the level of effort as a penalty for a low public contribution. Moreover, looking at the total effect we can conclude that this penalty impact more than offset the positive effect of the public intervention that is mediated through the level of investment.

\section{Discussion and Conclusion}

In the paper we propose an experiment to test a theoretical model. In the game we have two sequential tasks to be performed. The private agent must decide the level of investment sustaining a cost and therefore it must set the level of costly effort with the aim of increasing the probability to achieve higher final outcomes. A public regulator can decide to transfer part of his benefit (social surplus) coming from the project by either a linear transfer that increases with the level of total investment (benefit-sharing governance), or with the partial reimbursement of the investment cost (cost-sharing governance). The public intervention can be made before or after the investment decision, but always before the effort choice.

On the one hand, through the experiment we confirm some main results of the model. Precisely, a cost-sharing is always more effective than a benefit-sharing governance to boost the level of investment. Moreover, it is always better for the government to define ex-ante the level of public participation rather than ex-post. On the other hand, the theoretical model cannot completely explain results on the level of effort. Precisely, it is not only the case that the public intervention does not 
affect the level of effort, but it even negatively impacts the effort level decision of the private agent. The result is explained by the decision of the private agent to penalize the government in the case of a low level of public contribution. This penalty is higher when the public contribution is defined expost, i.e., after the investment choice. ${ }^{9}$

First, this result is interesting from a theoretical point of view since it helps to understand the behavioral functioning of a sequential principal-agent game. In the paper we discovered a reciprocity behavior deriving from the fact that the private agent react to an unfair action by the public principal (low level of contribution)With our experiment we detected this effect empirically, and we presented a possible channel to interpret negative effect on long-term agent outcomes of contribution on earlystage investment by the principal.

Second, the study has also several policy implications. In fact, whenever the government aims at boosting the level and the probability of success of uncertain investment with social consequences, he must also consider which will be the effect of his intervention in the long-run. Many investment in innovation, adaptation to climate change or bioeconomy do not only need a large amount of initial funding to be implemented, but it is the management stage that allows the government to achieve the final goals in the form of long-term economic and sustainable growth, clean and secure energy, or high level of employment rate. Governments intervene in several strategic sectors to sustain longterm investment. Prominent examples are energy (Jeffrey et al., 2014), innovation (Widdus, 2001), and ecological restoration policies (Borgstrom et al., 2016). In such cases private returns are not sufficient to stimulate sufficient investment, while social returns are relevant, especially in the longrun (Sgroi et al., 2016; Jeffrey et al., 2014). Public funding is normally focused on the early stages of the project. Thereafter, the high level of future uncertainty makes the public control during the implementation stage problematic; evidences of these difficulties are experienced in may real-world programs that have been found found to be not effective in the long-run (Borgstrom et al., 2016; Wellington and Lewis, 2016; Jeffrey et al., 2014). In our experiment we go further showing that when the public funding is scarce with respect to optimal values, and it is defined after the investment decision, then the public intervention can also be detrimental for the creation of long-term private incentives. This issue is even more important in these times of financial restrictions and increasingly tight budget constraints, where public policies are defined on too short periods relative to the stakes for which projects should be developed (Bernini and Pellegrin, 2011).

For all these reasons public funders of these projects are moving away from just supporting project or capital costs in favor of strengthening the organization' position by supporting its development costs. Such coordination can be realized through the realization of Public-Private Partnerships (PPPs) allowing an optimal sharing of risks, costs and tasks between public and private actors (Wellington and Lewis, 2016; Widdus, 2001). Thanks to these partnerships the public agent can keep the control in these projects providing private agents enough incentives to pursue long-term goals.

This statement starts to be highlighted also in institutional reports; for instance, according to the World Bank PPP "offers an approach to address key financing challenges to accelerate investments in low-emission projects" (Baietti, 2013). The recognition of the relevance of such partnerships before defining the long-term investment strategy is fundamental and can allow local and central public institutions to integrate their public policies with more up-to-date private information about future challenges, and considering both short and long-term effects of their strategic programs.

\footnotetext{
${ }^{9}$ In such a case, the government has a lower incentive to intervene, and the private agent has a higher incentive to penalize the public behavior.
} 


\section{References}

Andreoni, J. (1988). Why free ride?: Strategies and learning in public goods experiments. Journal of Public Economics, 37(3): 291 - 304.

Andreoni, J., Erard, B., \& Feinstein, J. (1998). Tax Compliance. Journal of Economic Literature, 36(2): $818-860$.

Audretsch, D. B., Link, A. N., and Scott, J. T. (2002). Public/private technology partnerships: evaluating sbir-supported research. Research Policy, 31(1): 145 - 158.

Baietti, A. (2013). Green infrastructure finance: a public-private partnership approach to climate finance. Technical report.

Bergstrom, T., Blume, L., and Varian, H. (1986). On the private provision of public goods. Journal of Public Economics, 29(1): 25 - 49.

Bernini, C. and Pellegrin, G. (2011). How are growth and productivity in private firms affected by public subsidy? Evidence from a regional policy. Regional Science and Urban Economics, 41(3): $253-265$.

Blanco, M., Engelmann, D., and Normann, H. T. (2011). A within-subject analysis of other regarding preferences. Games and Economic Behavior, 72(2): 321 - 338.

Borgstrom, S., Zachrisson, A., and Eckerberg, K. (2016). Funding ecological restoration policy in practic-patterns of short-termism and regional biases. Land Use Policy, 52: 439 - 453.

Cerqua, A. and Pellegrini, G. (2014). Do subsidies to private capital boost firms' growth? a multiple regression discontinuity design approach. Journal of Public Economics, 109: 114 - 126.

Chakravarty, S. and Roy, J. (2009). Recursive expected utility and the separation of attitudes towards risk and ambiguity: an experimental study. Theory and Decision, 66(3): 199 - 228.

Charness, Gary, and Matthew Rabin. (2002). Understanding Social Preferences with Simple Tests. Quarterly Journal of Economics, 117(3): 817 - 869.

Clarysse, B., Wright, M., and Mustar, P. (2009). Behavioural additionality of r\&d subsidies: A learning perspective. Research Policy, 38(10): 1517 - 1533.

Clausen, T. H. (2009). Do subsidies have positive impacts on $r \& d$ and innovation activities at the firm level? Structural Change and Economic Dynamics, 20(4): 239 - 253.

de Blasio, G., Fantino, D., and Pellegrini, G. (2011). Evaluating the impact of innovation incentives: evidence from an unexpected shortage of funds. Temi di discussione (Economic working papers) 792, Bank of Italy, Economic Research and International Relations Area.

Dufwenberg, M. and Kirchsteiger, G. (2004). A theory of sequential reciprocity. Games and Economic Behavior, 47(2): 268 - 298.

Falk, R. (2007). Measuring the effects of public support schemes on firms' innovation activities: Survey evidence from austria. Research Policy, 36(5): 665 - 679.

Fehr, S. and Schmidt, K. (1999). A theory of fairness competition and cooperation. Quarterly Journal of Economics, 114(3): 817 - 868.

Gallini, N. and Scotchmer, S. (2002). Intellectual Property: When Is It the Best Incentive System? In Innovation Policy and the Economy, Volume 2, NBER Chapters, pp. 51 - 78. National Bureau of Economic Research, Inc.

Georghiou, L. (1998). Issues in the evaluation of innovation and technology policy. In OECD, editor, Policy Evaluation in Innovation and Technology: Towards Best Practices, Chapter 3, pp. 698 -701 . 
Gonzalez, X., Jaumandreu, J., and Pazo, C. (2005). Barriers to Innovation and Subsidy Effectiveness. RAND Journal of Economics, 36(4): 930 - 949.

Hart, O. (2003). Incomplete contracts and public ownership: Remarks, and an application to public-private partnerships. Economic Journal, 113(486): C69 - C76.

Hart, O. D. (1988). Incomplete Contracts and the Theory of the Firm. Journal of Law, Economics and Organization, 4(1): 119 - 139.

Heijs, J. (2003). Freerider behaviour and the public finance of r\&d activities in enterprises: the case of the spanish low interest credits for r\&d. Research Policy, 32(3): 445 - 461.

Heller, A. H. and Eisenberg, R. S. (1998). Can patents deter innovation? The anticommons in biomedical research. Science, 280(5364): $698-701$.

Holt, C. A. and Laury, S. K. (2002). Risk aversion and incentive effects. American Economic Review, 92(5): 1644 - 1655.

Hoppe, E. I., Kusterer, D. J., and Schmitz, P. W. (2013). Public private partnerships versus traditional procurement: An experimental investigation. Journal of Economic Behavior \& Organization, 89(C): 145 - 166.

Huck, S., Seltzer, A. J., and Wallace, B. (2011). Deferred compensation in multiperiod labor contracts: An experimental test of lazear's model. American Economic Review, 101(2): 819 - 843.

Imai, K., Keele, L., and Tingley, D. (2010). A general approach to causal mediation analysis. Psychological Methods, 15(4): 309 - 334.

Jaumotte, F. and Pain, N. (2005). An overview of public policies to support innovation. OECD Economics Department Working Papers, (456).

Jeffrey, H., Sedgwick, J., and Gerrard, G. (2014). Public funding for ocean energy: A comparison of the $\{\mathrm{UK}\}$ and u.s. Technological Forecasting and Social Change, 84: $155-170$.

Lazear, E. P. (1979). Why Is There Mandatory Retirement? Journal of Political Economy, 87(6): $1261-1284$.

Lerner, J. (1999). The Government as Venture Capitalist: The Long-Run Impact of the SBIR Program. The Journal of Business, 72(3): 285 - 318.

Luukkonen, T. (2000). Additionality of $\{E U\}$ framework programmes. Research Policy, 29(6): $711-724$.

Nieken, P. and Schmitz, P. W. (2012). Repeated moral hazard and contracts with memory: A laboratory experiment. Games and Economic Behavior, 75(2): 1000 - 1008.

Ohlendorf, S. and Schmitz, P. W. (2012). Repeated Moral Hazard And Contracts With Memory: The Case Of Risk Neutrality. International Economic Review, 53(2): 433 - 452.

Olsen, S. and Fearnley, N. (2014). Policy transfer of public transport funding schemes -The case of Norway. Research in Transportation Economics, 48(C): 429 - 433.

Sgroi, F., FoderÃ, M., Dana, L.-P., Mangiapane, G., Tudisca, S., Trapani, A. M. D., and Testa, R. (2016). Evaluation of payment for ecosystem services in mediterranean forest: An empirical survey. Ecological Engineering, 90: 399 - 404.

Tirole, J. (1999). Incomplete contracts: Where do we stand? Econometrica, 67(4):741-781.

Wellington, J. F. and Lewis, S. A. (2016). A method for evaluating the funding of components of natural resource and conservation projects. Environmental Impact Assessment Review, 57: 40 - 45.

Widdus, R. (2001). Public-private partnerships for health: their main targets, their diversity, and their future directions. Bulletin of the World Health Organization, 79: 713 - 720. 


\section{Figures and Tables}

Figure 1: Time-lines for the five different treatments

\begin{tabular}{|c|c|c|}
\hline & Private & \\
\hline $\begin{array}{c}\text { The player X chooses the level } \\
\text { of Investment } I\end{array}$ & $\begin{array}{l}\text { The player } X \text { chooses a } \\
\text { number of white balls to } \\
\text { buy } B\end{array}$ & $\begin{array}{l}\text { The computer draws a } \\
\text { ball from the urn }\end{array}$ \\
\hline
\end{tabular}

\section{Ex-ante BS}

$\begin{array}{ccc}\text { The player } X \text { chooses the } \\ \begin{array}{c}\text { Thansfer } \mathrm{C} \\ \text { The player } Y \text { chooses the level } \\ \text { of Investment } I\end{array} & \begin{array}{c}\text { The player } Y \text { chooses a } \\ \text { number of white balls to } \\ \text { buy } B\end{array} & \begin{array}{c}\text { The computer draws a } \\ \text { ball from the urn }\end{array}\end{array}$

\section{Ex-post BS}

The player $\mathrm{X}$ chooses the level of Investment $I$
The player $Y$ chooses the transfer $C$
The player $\mathrm{X}$ chooses a number of white balls to buy $B$
The computer draws a ball from the urn

\section{Ex-ante CS}

The player $X$ chooses the
$\begin{gathered}\text { The } T \\ \text { rate } T\end{gathered}$
$\begin{array}{ccc}\text { of Investment } I & \text { The player } Y \text { chooses a } & \text { The computer draws a } \\ \text { ball from the urn }\end{array}$

\section{Ex-post CS}

The player $\mathrm{X}$ chooses the level of Investment $I$
The player $\mathrm{Y}$ chooses the rate $T$
The player $X$ chooses a number of white balls to buy $B$
The computer draws a ball from the urn 
Figure 2: Average investment per treatment

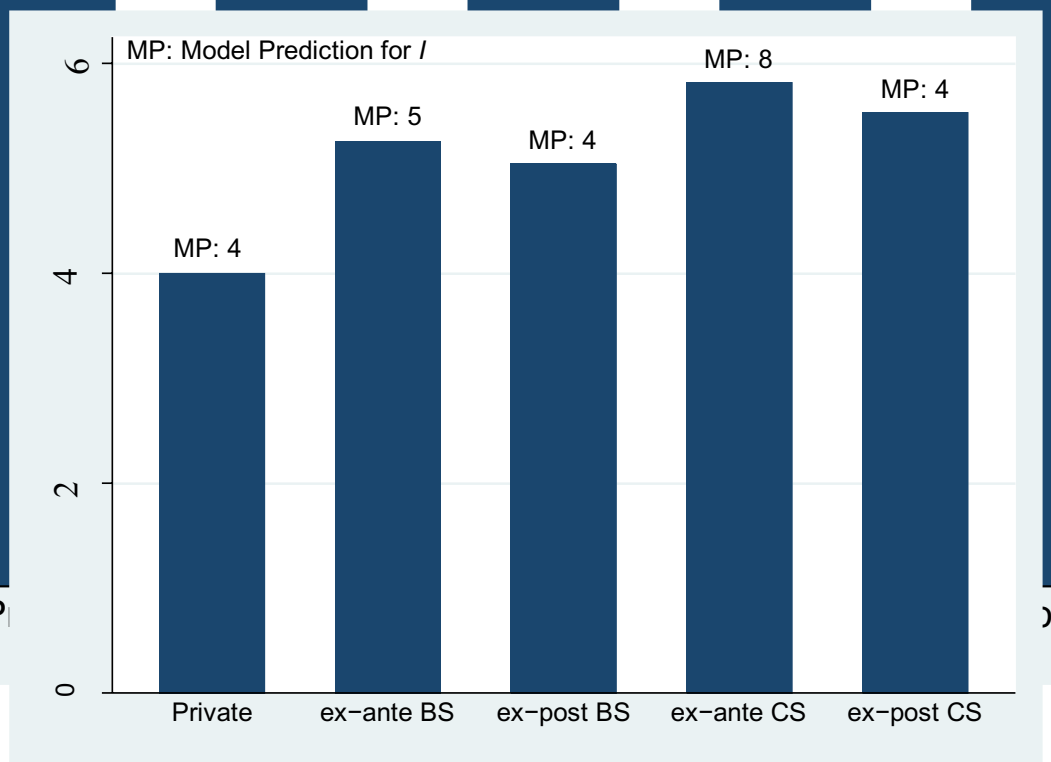

Figure 3: Investment density per treatment

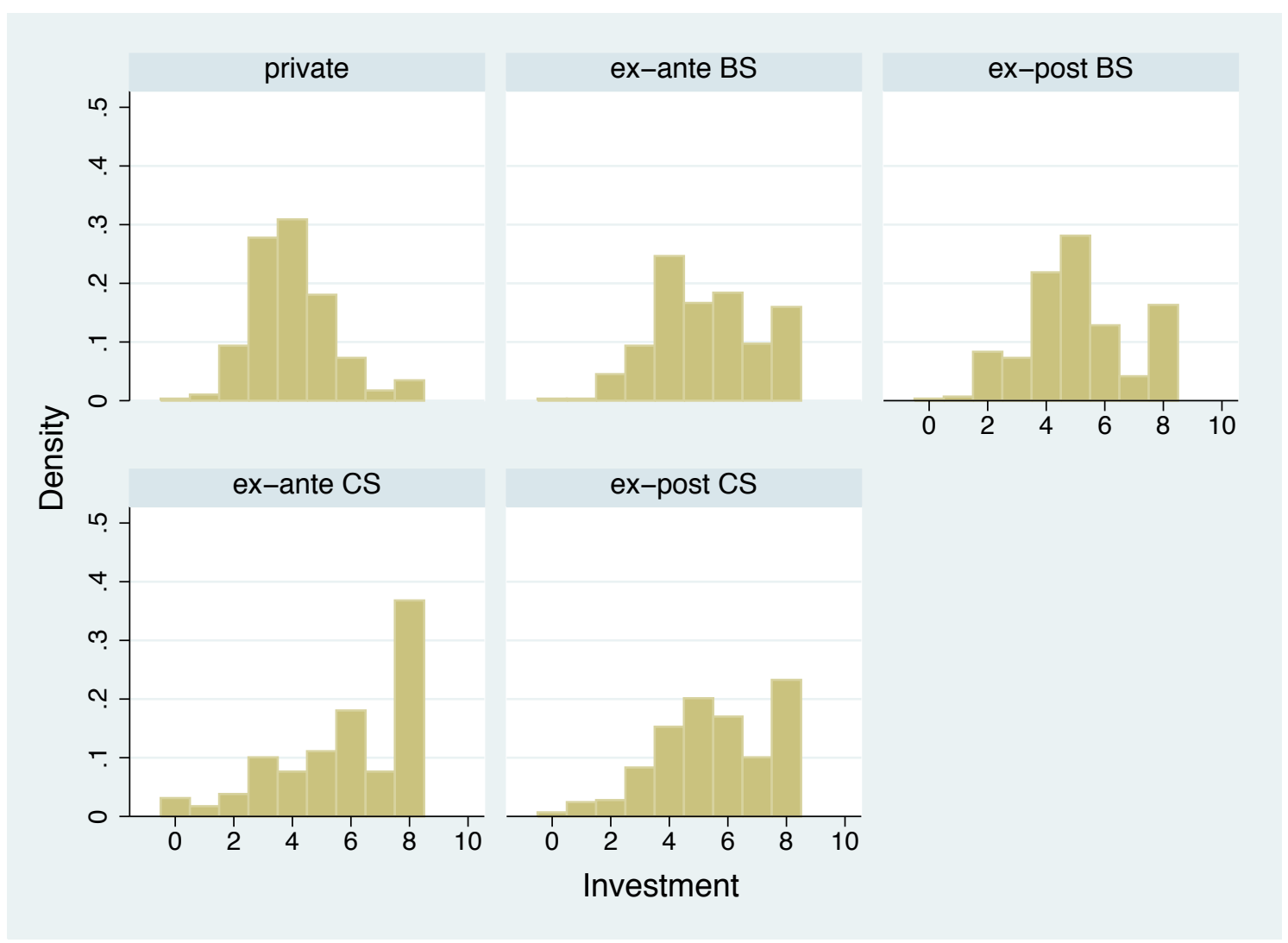


Table 1: Definition of variables

\begin{tabular}{|c|c|c|}
\hline DIMENSION & VARIABLE & DEFINITION \\
\hline \multicolumn{3}{|c|}{ "DEPENDANT VARIABLES } \\
\hline \multirow{2}{*}{\multicolumn{2}{|c|}{$I_{i c p t}$}} & Equals to the level of investment chosen by the private agent each period \\
\hline & & Equals to the level of effort chosen by the private agent each period \\
\hline \multicolumn{3}{|c|}{ INDEPENDANT VARIABLES } \\
\hline \multirow{6}{*}{$\begin{array}{l}\text { Explanatory } \\
\text { variables }\end{array}$} & $\bar{C}$ & Equals to the level of transfer under the BS treatments \\
\hline & $T$ & Equals to the level of cost-sharing parameter under the CS treatments \\
\hline & ex-anteBS & Equals to 1 for the ex-ante BS treatment; 0 otherwise \\
\hline & ex-postBS & Equals to 1 for the ex-post BS treatment; 0 otherwise \\
\hline & ex-anteCS & Equals to 1 for the ex-ante CS treatment; 0 otherwise \\
\hline & ex-postCS & Equals to 1 for the ex-post CS treatment; 0 otherwise \\
\hline \multirow{11}{*}{$\begin{array}{l}\text { Control } \\
\text { variables }\end{array}$} & av_risk_low & Equals to 1 if the private agent switches to the risky option either at line 8 or 9 or 10 \\
\hline & av_risk_med & Equals to 1 if the private agent switches to the risky option either at line 4 or 5 or 6 or 7 \\
\hline & av_risk_high & Equals to 1 if the private agent switches to the risky option either at line 1 or 2 or 3 \\
\hline & $a v \_$ineq_low & Equals to 1 if the private agent switches to the right option either at line 8 or 9 or 10 \\
\hline & $a v \_$ineq_med & Equals to 1 if the private agent switches to the right option either at line 4 or 5 or 6 or 7 \\
\hline & $a v \_$ineq_high & Equals to 1 if the private agent switches to the right option either at line 1 or 2 or 3 \\
\hline & age & Equals to the age of the participants (private actor) \\
\hline & male & Equals to 1 if the participant (private actor) is a male \\
\hline & WrongAnsw & $\begin{array}{l}\text { Equals to the number of wrong answers at the final understanding questionnaire of the } \\
\text { participant (private actor) }\end{array}$ \\
\hline & learning inv & Equals to 1 if the investment choice at period $t$ is equal to the one at $t-1$ \\
\hline & learning eff & Equals to 1 if the effort choice at period $t$ is equal to the one at $t-1$ \\
\hline
\end{tabular}


Table 2: Investment Estimation

\begin{tabular}{|c|c|c|c|c|c|c|c|}
\hline & $\begin{array}{c}\text { (Private) } \\
\text { Investment }\end{array}$ & $\begin{array}{c}\text { (ex-ante BS) } \\
\text { Investment }\end{array}$ & $\begin{array}{c}\text { (ex-post BS) } \\
\text { Investment }\end{array}$ & $\begin{array}{c}\text { (ex-ante CS) } \\
\text { Investment }\end{array}$ & $\begin{array}{c}\text { (ex-post CS) } \\
\text { Investment }\end{array}$ & $\begin{array}{l}\text { (ex-ante all) } \\
\text { Investment }\end{array}$ & $\begin{array}{l}\text { (ex-post all) } \\
\text { Investment }\end{array}$ \\
\hline av_risk_med & $\begin{array}{l}-0.216 \\
(-0.34)\end{array}$ & $\begin{array}{l}-0.187 \\
(-1.24)\end{array}$ & $\begin{array}{l}-0.0533 \\
(-0.17)\end{array}$ & $\begin{array}{c}-0.958^{* *} \\
(-3.36)\end{array}$ & $\begin{array}{c}2.323^{* *} \\
(4.43)\end{array}$ & $\begin{array}{c}-0.0388 \\
(-0.19)\end{array}$ & $\begin{array}{l}0.741^{*} \\
(2.84)\end{array}$ \\
\hline o.av_risk_high & $\begin{array}{c}0 \\
(.)\end{array}$ & $\begin{array}{l}-0.413 \\
(-0.75)\end{array}$ & $\begin{array}{l}0.0192 \\
(0.03)\end{array}$ & $\begin{array}{l}-0.734 \\
(-1.53)\end{array}$ & $\begin{array}{l}1.191^{*} \\
(2.25)\end{array}$ & $\begin{array}{l}-0.244 \\
(-0.79)\end{array}$ & $\begin{array}{l}-0.408 \\
(-1.04)\end{array}$ \\
\hline$a v \_$ineq_med & $\begin{array}{l}-0.734^{*} \\
(-3.00)\end{array}$ & $\begin{array}{l}-0.212 \\
(-1.28)\end{array}$ & $\begin{array}{c}1.475^{* * *} \\
(5.07)\end{array}$ & $\begin{array}{r}0.246 \\
(0.82)\end{array}$ & $\begin{array}{l}-0.694^{*} \\
(-2.99)\end{array}$ & $\begin{array}{c}-0.427^{* *} \\
(-3.56)\end{array}$ & $\begin{array}{l}0.0943 \\
(0.54)\end{array}$ \\
\hline av_ineq_high & $\begin{array}{c}-1.371^{* *} \\
(-4.08)\end{array}$ & $\begin{array}{l}-0.716 \\
(-1.94)\end{array}$ & $\begin{array}{l}0.687^{*} \\
(2.91)\end{array}$ & $\begin{array}{c}0.548 \\
(1.08)\end{array}$ & $\begin{array}{l}-0.513 \\
(-1.47)\end{array}$ & $\begin{array}{l}-0.626 \\
(-1.95)\end{array}$ & $\begin{array}{l}-0.159 \\
(-0.74)\end{array}$ \\
\hline age & $\begin{array}{l}0.0128 \\
(0.32)\end{array}$ & $\begin{array}{l}0.113 \\
(2.00)\end{array}$ & $\begin{array}{c}0.0653^{*} \\
(2.64)\end{array}$ & $\begin{array}{c}0.130^{* * *} \\
(4.45)\end{array}$ & $\begin{array}{l}-0.0357 \\
(-1.57)\end{array}$ & $\begin{array}{c}0.0570^{*} \\
(2.22)\end{array}$ & $\begin{array}{c}0.0397^{*} \\
(2.75)\end{array}$ \\
\hline male & $\begin{array}{l}-0.507^{*} \\
(-2.39)\end{array}$ & $\begin{array}{c}0.816^{* * *} \\
(4.52)\end{array}$ & $\begin{array}{c}0.578^{* *} \\
(3.55)\end{array}$ & $\begin{array}{l}-0.0803 \\
(-0.28)\end{array}$ & $\begin{array}{l}0.206 \\
(0.66)\end{array}$ & $\begin{array}{l}-0.153 \\
(-1.29)\end{array}$ & $\begin{array}{l}0.217 \\
(1.49)\end{array}$ \\
\hline WrongAnsw & $\begin{array}{l}0.191^{*} \\
(2.71)\end{array}$ & $\begin{array}{l}0.0651 \\
(0.87)\end{array}$ & $\begin{array}{c}0.468^{* * *} \\
(11.93)\end{array}$ & $\begin{array}{l}-0.235^{*} \\
(-2.62)\end{array}$ & $\begin{array}{l}0.0626 \\
(0.78)\end{array}$ & $\begin{array}{c}-0.00932 \\
(-0.20)\end{array}$ & $\begin{array}{c}0.179^{* * *} \\
(5.69)\end{array}$ \\
\hline learning_inv & $\begin{array}{l}0.0526 \\
(0.26)\end{array}$ & $\begin{array}{l}-0.0882 \\
(-0.49)\end{array}$ & $\begin{array}{l}-0.0326 \\
(-0.22)\end{array}$ & $\begin{array}{l}0.395^{*} \\
(2.24)\end{array}$ & $\begin{array}{l}0.151 \\
(0.56)\end{array}$ & $\begin{array}{r}0.228 \\
(1.52)\end{array}$ & $\begin{array}{l}0.0488 \\
(0.38)\end{array}$ \\
\hline $\mathrm{C}$ & & $\begin{array}{c}2.302^{* * *} \\
(20.40)\end{array}$ & $\begin{array}{l}0.282 \\
(1.65)\end{array}$ & & & & \\
\hline $\mathrm{T}$ & & & & $\begin{array}{c}5.113^{* * *} \\
(15.60)\end{array}$ & $\begin{array}{l}0.585 \\
(2.04)\end{array}$ & & \\
\hline ex-ante BS & & & & & & $\begin{array}{c}1.276^{* * *} \\
(7.26)\end{array}$ & \\
\hline ex-ante CS & & & & & & $\begin{array}{c}1.937^{* * *} \\
(10.91)\end{array}$ & \\
\hline ex-ante CS & & & & & & & $\begin{array}{c}0.980^{* * * *} \\
(6.91)\end{array}$ \\
\hline ex-post CS & & & & & & & $\begin{array}{c}1.664^{* * *} \\
(11.44)\end{array}$ \\
\hline _cons & $\begin{array}{l}4.565^{*} \\
(3.04)\end{array}$ & $\begin{array}{l}0.397 \\
(0.35)\end{array}$ & $\begin{array}{l}0.858 \\
(1.25)\end{array}$ & $\begin{array}{l}1.820^{*} \\
(2.60)\end{array}$ & $\begin{array}{c}4.437^{* * *} \\
(5.49)\end{array}$ & $\begin{array}{c}3.164^{* * *} \\
(4.73)\end{array}$ & $\begin{array}{c}1.946^{* *} \\
(3.33)\end{array}$ \\
\hline $\begin{array}{l}N \\
\text { diff_cs-bs } \\
\text { t test }\end{array}$ & 288 & 288 & 288 & 288 & 288 & $\begin{array}{c}864 \\
0.661^{\text {*** }} \\
(9.185)\end{array}$ & $\begin{array}{c}864 \\
0.684^{* * *} \\
(5.379)\end{array}$ \\
\hline
\end{tabular}

$t$ statistics in parentheses

${ }^{*} p<0.05,{ }^{* *} p<0.01,{ }^{* * *} p<0.001$ 
Figure 4: Average effort per treatment

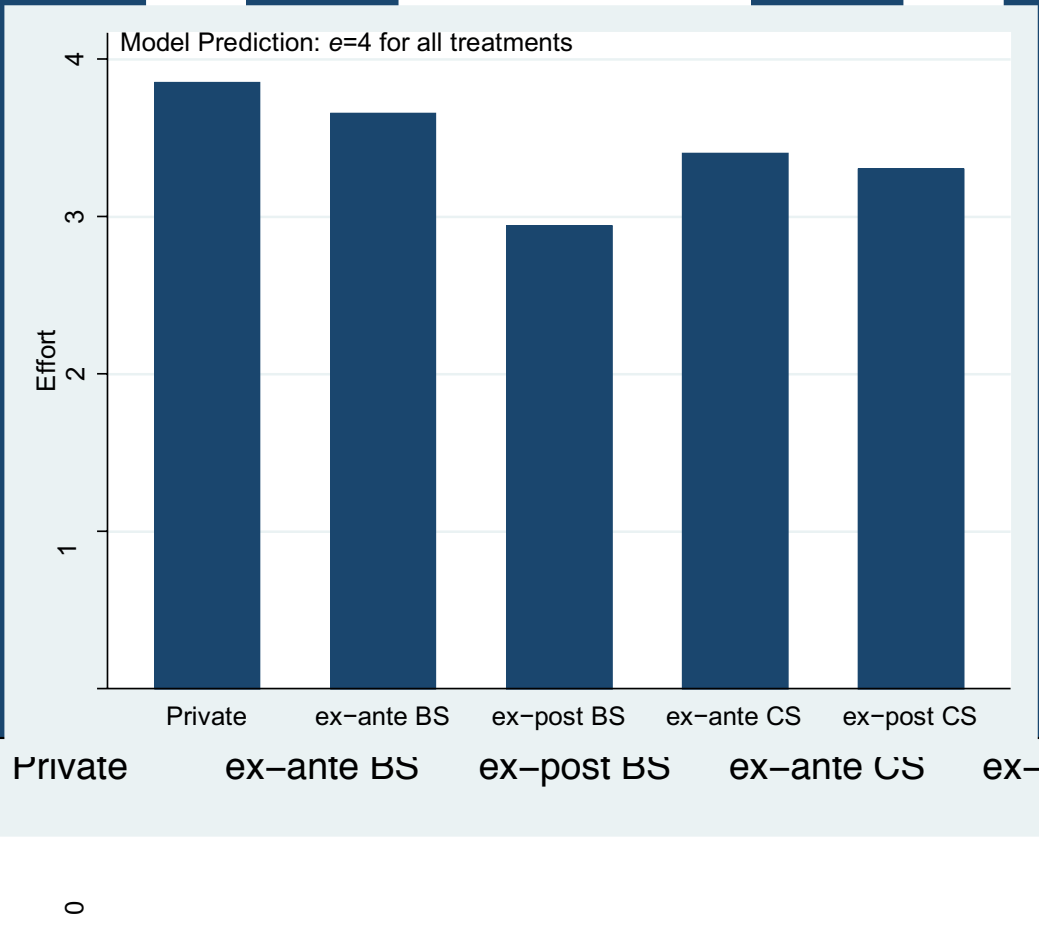

Figure 5: Effort density per treatment

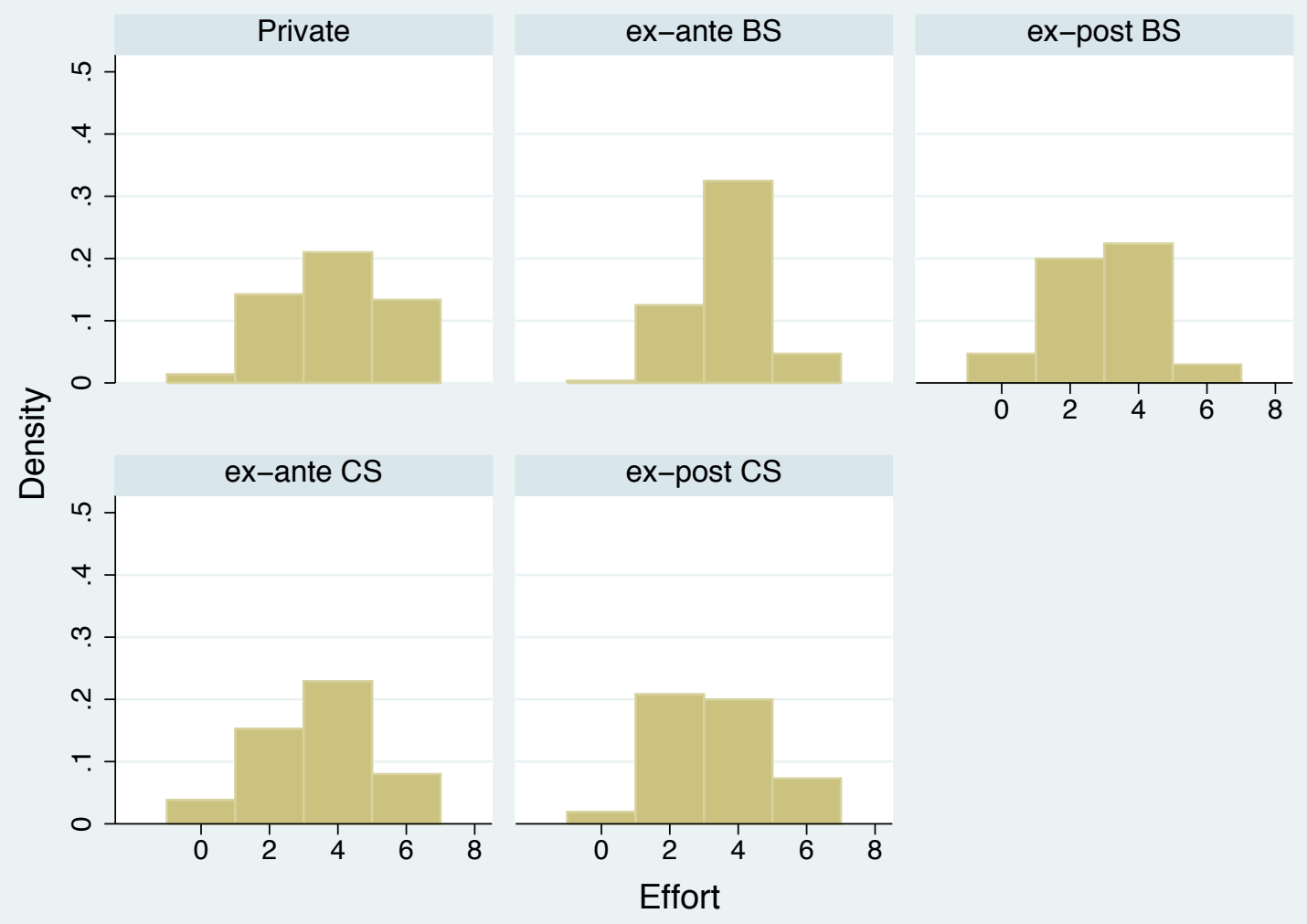


Table 3: Effort Estimation

\begin{tabular}{|c|c|c|c|c|c|c|c|}
\hline & $\begin{array}{l}\text { (Private) } \\
\text { Effort }\end{array}$ & $\begin{array}{c}\text { (ex-ante BS) } \\
\text { Effort }\end{array}$ & $\begin{array}{c}\text { (ex-post BS) } \\
\text { Effort }\end{array}$ & $\begin{array}{c}\text { (ex-ante CS) } \\
\text { Effort }\end{array}$ & $\begin{array}{c}\text { (ex-post CS) } \\
\text { Effort }\end{array}$ & $\begin{array}{c}\text { (ex-ante all) } \\
\text { Effort }\end{array}$ & $\begin{array}{c}\text { (ex-post all) } \\
\text { Effort }\end{array}$ \\
\hline av_risk_med & $\begin{array}{c}2.752^{* * * *} \\
(4.85)\end{array}$ & $\begin{array}{c}-0.00484 \\
(-0.03)\end{array}$ & $\begin{array}{l}0.353 \\
(0.96)\end{array}$ & $\begin{array}{l}-0.291 \\
(-0.76)\end{array}$ & $\begin{array}{l}-0.742 \\
(-2.17)\end{array}$ & $\begin{array}{l}0.328^{*} \\
(1.98)\end{array}$ & $\begin{array}{l}0.448^{*} \\
(2.02)\end{array}$ \\
\hline o.av_risk_high & $\begin{array}{l}0 \\
(.)\end{array}$ & $\begin{array}{l}-0.203 \\
(-0.35)\end{array}$ & $\begin{array}{r}-0.0401 \\
(-0.07)\end{array}$ & $\begin{array}{r}-0.950^{* *} \\
(-4.06)\end{array}$ & $\begin{array}{l}-0.166 \\
(-0.39)\end{array}$ & $\begin{array}{r}-0.716^{* *} \\
(-2.85)\end{array}$ & $\begin{array}{l}0.117 \\
(0.36)\end{array}$ \\
\hline av_ineq_med & $\begin{array}{c}-0.857^{* *} \\
(-3.46)\end{array}$ & $\begin{array}{l}-0.348 \\
(-1.67)\end{array}$ & $\begin{array}{l}0.0842 \\
(0.35)\end{array}$ & $\begin{array}{l}0.149 \\
(0.36)\end{array}$ & $\begin{array}{l}-0.328 \\
(-1.36)\end{array}$ & $\begin{array}{l}-0.325^{*} \\
(-2.50)\end{array}$ & $\begin{array}{c}-0.429^{* *} \\
(-3.16)\end{array}$ \\
\hline av_ineq_high & $\begin{array}{l}-1.017^{*} \\
(-3.03)\end{array}$ & $\begin{array}{l}-0.330 \\
(-0.74)\end{array}$ & $\begin{array}{l}-0.184 \\
(-0.75)\end{array}$ & $\begin{array}{l}-0.0500 \\
(-0.16)\end{array}$ & $\begin{array}{l}-0.620^{*} \\
(-2.93)\end{array}$ & $\begin{array}{l}-0.116 \\
(-0.57)\end{array}$ & $\begin{array}{c}-0.565^{* * *} \\
(-3.42)\end{array}$ \\
\hline age & $\begin{array}{c}0.131^{* *} \\
(3.58)\end{array}$ & $\begin{array}{l}-0.0331 \\
(-0.59)\end{array}$ & $\begin{array}{c}0.0550^{*} \\
(2.52)\end{array}$ & $\begin{array}{l}-0.0104 \\
(-0.24)\end{array}$ & $\begin{array}{l}-0.0522 \\
(-2.14)\end{array}$ & $\begin{array}{l}-0.0399 \\
(-1.77)\end{array}$ & $\begin{array}{l}0.0206 \\
(1.23)\end{array}$ \\
\hline male & $\begin{array}{l}-1.397^{* * * *} \\
5.82)\end{array}$ & $\begin{array}{l}-0.405^{*} \\
(-2.47)\end{array}$ & $\begin{array}{c}-0.652^{* * * *} \\
(-7.51)\end{array}$ & $\begin{array}{l}-0.158 \\
(-0.44)\end{array}$ & $\begin{array}{l}0.418^{*} \\
(2.34)\end{array}$ & $\begin{array}{c}-0.689^{* * * *} \\
(-5.83)\end{array}$ & $\begin{array}{c}-0.444^{* * * *}(- \\
(-3.63)\end{array}$ \\
\hline WrongAnsw & $\begin{array}{c}-0.327^{* *} \\
(-3.82)\end{array}$ & $\begin{array}{l}0.132 \\
(1.36)\end{array}$ & $\begin{array}{l}-0.102 \\
(-1.20)\end{array}$ & $\begin{array}{l}-0.260 \\
(-2.01)\end{array}$ & $\begin{array}{l}0.0193 \\
(0.30)\end{array}$ & $\begin{array}{l}-0.109^{*} \\
(-2.54)\end{array}$ & $\begin{array}{l}-0.0397 \\
(-0.90)\end{array}$ \\
\hline learning_eff & $\begin{array}{l}-0.156^{*} \\
(-2.36)\end{array}$ & $\begin{array}{l}-0.159 \\
(-1.03)\end{array}$ & $\begin{array}{r}-0.0341 \\
(-0.18)\end{array}$ & $\begin{array}{l}0.0138 \\
(0.09)\end{array}$ & $\begin{array}{l}-0.162 \\
(-0.86)\end{array}$ & $\begin{array}{l}-0.0369 \\
(-0.36)\end{array}$ & $\begin{array}{l}-0.0905 \\
(-0.86)\end{array}$ \\
\hline Investment & & $\begin{array}{l}-0.0507 \\
0.71)\end{array}$ & $\begin{array}{l}0.161^{*} \\
(2.61)\end{array}$ & $\begin{array}{c}0.204^{* *} \\
(3.17)\end{array}$ & $\begin{array}{l}0.0729 \\
(1.18)\end{array}$ & $\begin{array}{c}0.166^{\text {*** }} \\
(5.34)\end{array}$ & $\begin{array}{l}0.116^{* *}(- \\
(3.29)\end{array}$ \\
\hline $\mathrm{C}$ & & $\begin{array}{r}0.815^{* * *} \\
(5.44)\end{array}$ & $\begin{array}{r}0.700^{* *} \\
(4.00)\end{array}$ & & & & \\
\hline $\mathrm{T}$ & & & & $\begin{array}{l}0.367 \\
(0.83)\end{array}$ & $\begin{array}{c}1.167^{* *} \\
(4.34)\end{array}$ & & \\
\hline ex-ante BS & & & & & & $\begin{array}{r}-0.480^{* * *} \\
(-3.92)\end{array}$ & \\
\hline ex-ante CS & & & & & & $\begin{array}{r}-0.482^{* *} \\
(-3.22)\end{array}$ & \\
\hline ex-post BS & & & & & & & $\begin{array}{r}-1.035^{* * *} \\
(-7.71)\end{array}$ \\
\hline ex-post CS & & & & & & & $\begin{array}{r}-0.772^{* * *} \\
(-5.20)\end{array}$ \\
\hline _cons & $\begin{array}{l}0.688 \\
(0.65)\end{array}$ & $\begin{array}{c}4.185^{* *} \\
(3.44)\end{array}$ & $\begin{array}{l}0.712 \\
(1.16)\end{array}$ & $\begin{array}{l}3.201^{*} \\
(2.99)\end{array}$ & $\begin{array}{c}4.511^{* * * *} \\
(6.67)\end{array}$ & $\begin{array}{c}4.658^{* * * *} \\
(8.24)\end{array}$ & $\begin{array}{c}3.284^{* * * *} \\
(8.21)\end{array}$ \\
\hline $\begin{array}{l}N \\
\text { diff_cs-bs } \\
\text { t test }\end{array}$ & 288 & 288 & 288 & 288 & 288 & $\begin{array}{c}864 \\
-0.00215 \\
(-0.0170)\end{array}$ & $\begin{array}{c}864 \\
0.263^{*} \\
(1.986)\end{array}$ \\
\hline
\end{tabular}

$t$ statistics in parentheses

${ }^{*} p<0.05,{ }^{* *} p<0.01,{ }^{* * *} p<0.001$ 
Figure 6: Effort for level of $C$ (ex-ante and ex-post) benefit-sharing treatment
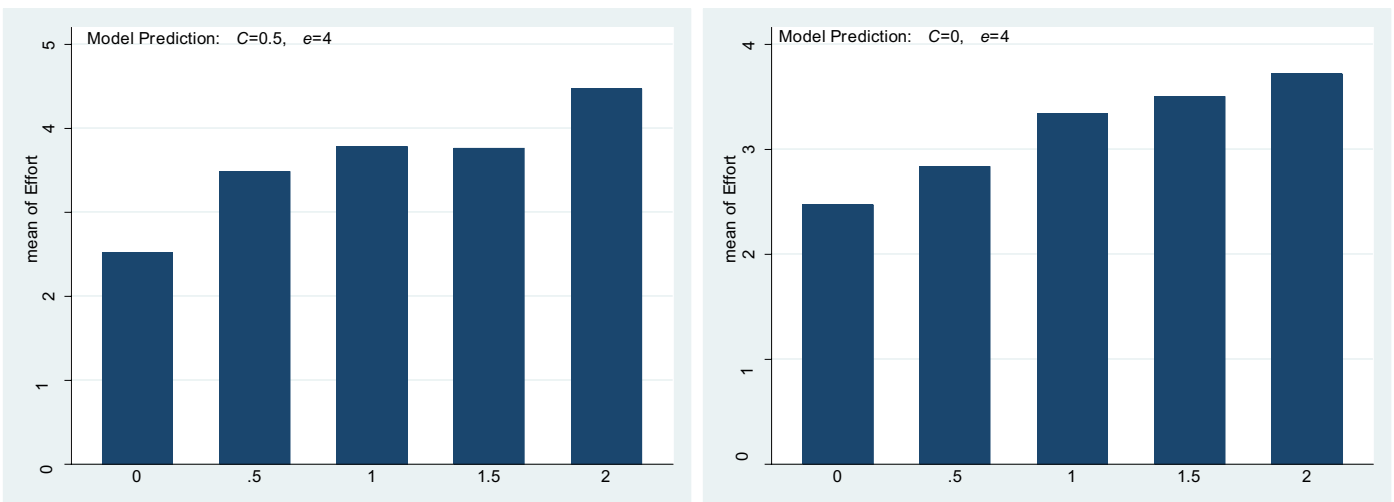

Figure 7: Effort for level of $\mathrm{T}$ (ex-ante and ex-post) cost-sharing treatment
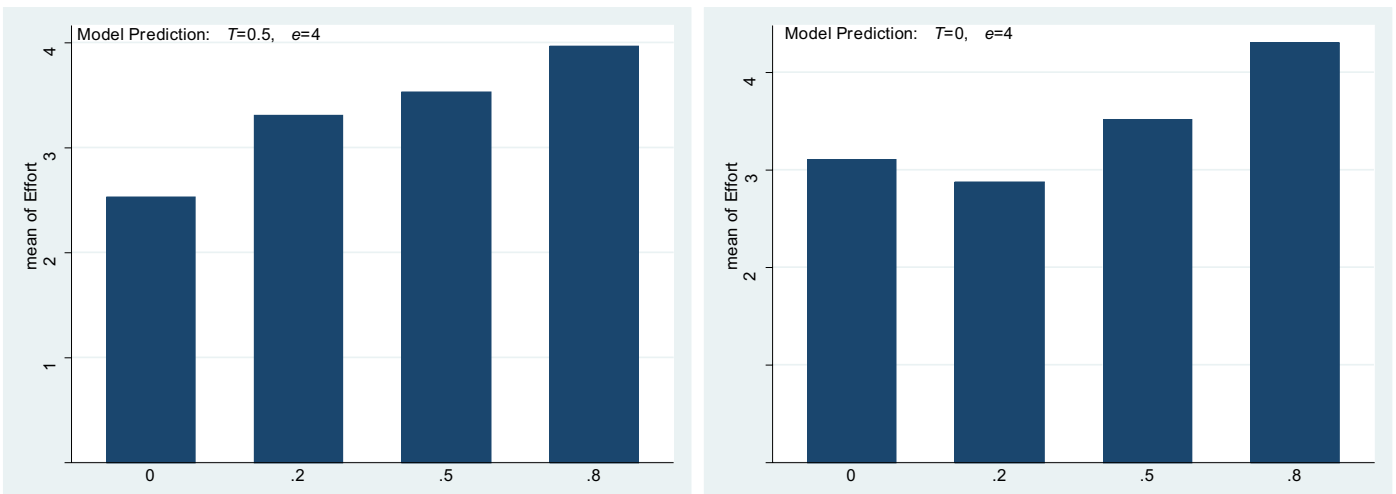
Table 4: Decomposition of total effect

\begin{tabular}{|c|c|c|c|c|}
\hline ex-ante BS (C variable) & Effect & Mean & {$[95 \%$ Conf. } & Interval] \\
\hline & ACME & -.1259907 & -.4342752 & .1955781 \\
\hline & Direct Effect & .8163883 & .5198998 & 1.115878 \\
\hline & Total Effect & .6903976 & .4246962 & .9501777 \\
\hline & $\%$ of Tot Eff mediated & -.182594 & -.2966651 & -.132597 \\
\hline \multirow[t]{5}{*}{ ex-post BS (C variable) } & Effect & Mean & {$[95 \%$} & Interval] \\
\hline & ACME & .0446415 & -.005692 & .1253956 \\
\hline & Direct Effect & .7014499 & .3549499 & 1.051457 \\
\hline & Total Effect & .7460915 & .3933415 & 1.106046 \\
\hline & $\%$ of Tot Eff mediated & .0592653 & .0403614 & .1134938 \\
\hline \multirow[t]{5}{*}{ ex-ante CS ( $T$ variable) } & Effect & Mean & {$[95 \%$} & Interval] \\
\hline & ACME & 1.049351 & .4351839 & 1.735076 \\
\hline & Direct Effect & .3700969 & -.5002173 & 1.24922 \\
\hline & Total Effect & 1.419448 & .913032 & 1.897076 \\
\hline & $\%$ of Tot Eff mediated & .7410393 & .5531412 & 1.149304 \\
\hline \multirow[t]{5}{*}{ ex-post CS (T variable) } & Effect & Mean & {$[95 \%$} & Interval] \\
\hline & ACME & .0471926 & -.0285116 & .1713846 \\
\hline & Direct Effect & 1.169053 & .6363516 & 1.707146 \\
\hline & Total Effect & 1.216246 & .7188289 & 1.714857 \\
\hline & $\%$ of Tot Eff mediated & .0384786 & .0275199 & .0656568 \\
\hline \multirow[t]{5}{*}{ ex-ante all (BS dummy) } & Effect & Mean & {$[95 \%$} & Interval] \\
\hline & ACME & .2094339 & .129042 & .3031646 \\
\hline & Direct Effect & -.4844145 & -.7197352 & -.2439711 \\
\hline & Total Effect & -.2749807 & -.5050497 & -.0444281 \\
\hline & $\%$ of Tot Eff mediated & -.7501638 & -3623857 & -.3928498 \\
\hline \multirow[t]{5}{*}{ ex-ante all (CS dummy) } & Effect & Mean & {$[95 \%$} & Interval] \\
\hline & ACME & .3200665 & .2016183 & .457697 \\
\hline & Direct Effect & -.4874952 & -.7749565 & -.193776 \\
\hline & Total Effect & -.1674287 & -.4330463 & .098011 \\
\hline & $\%$ of Tot Eff mediated & -1.580173 & -1.822604 & 1.529902 \\
\hline \multirow[t]{5}{*}{ ex-post all (BS dummy) } & Effect & Mean & {$[95 \%$} & Interval] \\
\hline & ACME & .1136375 & .0459914 & .1920386 \\
\hline & Direct Effect & -1039717 & -1297611 & -.7762086 \\
\hline & Total Effect & -.9260793 & -1176282 & -.6727777 \\
\hline & $\%$ of Tot Eff mediated & -.1223299 & -.168908 & -.0966074 \\
\hline \multirow[t]{5}{*}{ ex-post all (CS dummy) } & Effect & Mean & {$[95 \%$} & Interval] \\
\hline & ACME & .1930154 & .079396 & .320745 \\
\hline & Direct Effect & -.7768148 & -1062047 & -.4853735 \\
\hline & Total Effect & -.5837994 & -.8454677 & -.3153427 \\
\hline & $\%$ of Tot Eff mediated & -.3301278 & -.6121535 & -.2282943 \\
\hline
\end{tabular}




\section{Appendix}

\section{Appendix A}

Solving the problem through a backward induction strategy, we first derive the first best level of effort:

Second, we get the level of investment at the optimum:

$$
\begin{gathered}
\max _{e} W+U=\frac{e}{k}\left(R^{h}+S^{h}\right)+\left(1-\frac{e}{k}\right)\left(R^{l}+S^{l}\right)-\frac{e^{2}}{q k} I-\frac{I^{2}}{p} \\
\frac{d(W+U)}{d e}=\frac{(\Delta R+\Delta S) I}{k}-\frac{2 e}{q k} I=0 \\
e^{f b}=\frac{q(\Delta R+\Delta S)}{2}
\end{gathered}
$$

$$
\begin{gathered}
\max _{I} W+U=\frac{e}{k}\left(R^{h}+S^{h}\right)+\left(1-\frac{e}{k}\right)\left(R^{l}+S^{l}\right)-\frac{e^{2}}{q k} I-\frac{I^{2}}{p} \\
\frac{d(W+U)}{d I}=\frac{(\Delta R+\Delta S) e}{k}+R^{l}+S^{l}-\frac{e^{2}}{q k}-2 \frac{I}{p}=0 \\
I^{f b}=p \frac{q(\Delta R+\Delta S)^{2}+4 k R^{l}+4 k S^{l}}{8 k}
\end{gathered}
$$

\section{Appendix B}

Solving the problem through a backward induction strategy, we first derive the optimal level of effort under the private scenario:

Second, we get the level of investment at the optimum:

$$
\begin{gathered}
\max _{e} U=\frac{e}{k} R^{h}+\left(1-\frac{e}{k}\right) R^{l}-\frac{e^{2}}{q k} I-\frac{I^{2}}{p} \\
\frac{d(U)}{d e}=\frac{\Delta R I}{k}-\frac{2 e}{q k} I=0 \\
e^{p r}=\frac{q \Delta R}{2}
\end{gathered}
$$

$$
\begin{gathered}
\max _{I} U=\frac{e}{k} R^{h}+\left(1-\frac{e}{k}\right) R^{l}-\frac{e^{2}}{q k} I-\frac{I^{2}}{p} \\
\frac{d(U)}{d I}=\frac{\Delta R e}{k}+R^{l}-\frac{e^{2}}{q k}-2 \frac{I}{p}=0 \\
I^{f b}=p \frac{q(\Delta R)^{2}+4 k R^{l}}{8 k}
\end{gathered}
$$

\section{Appendix C}

Solving the problem through a backward induction strategy, we first derive the optimal level of effort:

$$
\begin{gathered}
\max _{e} U=\frac{e}{k} R^{h}+\left(1-\frac{e}{k}\right) R^{l}-\frac{e^{2}}{q k} I-\frac{I^{2}}{p}+C I \\
\frac{d(U)}{d e}=\frac{\Delta R I}{k}-\frac{2 e}{q k} I=0 \\
e^{b s}=\frac{q \Delta R}{2}
\end{gathered}
$$


Second, the levels of investment is set by maximizing the objective functions of the private agent:

$$
\begin{gathered}
\max _{I} U=\frac{e}{k} R^{h}+\left(1-\frac{e}{k}\right) R^{l}-\frac{e^{2}}{q k} I-\frac{I^{2}}{p}+C I \\
\frac{d(U)}{d I}=\frac{\Delta R e}{k}+R^{l}-\frac{e^{2}}{q k}-2 \frac{I}{p}+C=0 \\
I^{b s}(C)=p \frac{q(\Delta R)^{2}+4 k R^{l}+4 k C}{8 k}
\end{gathered}
$$

Finally, the public regulator sets the transfer anticipating what will be the optimal investment choice of the private agent:

$$
\begin{gathered}
\max _{C} W=\frac{e}{k} S^{h}+\left(1-\frac{e}{k}\right) S^{l}-(1+\lambda) C I^{b s}(C) \\
\frac{d(W)}{d C}=p \frac{q \Delta R}{4 k} \Delta S+S^{l}-(1+\lambda)\left(p C+p \frac{q(\Delta R)^{2}+4 k R^{l}}{8 k}\right)=0 \\
C^{b s}=\max \left\{\frac{q \Delta R \Delta S+2 k S^{l}}{4(1+\lambda) k}-\frac{q \Delta R^{2}+4 k R^{l}}{8 k}, 0\right\}
\end{gathered}
$$

Then, the value of the investment at the equilibrium is:

$$
I^{b s}=\max \left\{I^{p r}, \quad \frac{p\left[q \Delta R^{2}+4 k R^{l}\right]}{16 k}+\frac{p\left[q \Delta R \Delta S+2 k S^{l}\right]}{8(1+\lambda) k}\right\}
$$

\section{Appendix D}

Solving the problem through a backward induction strategy, we first derive the optimal level of effort:

$$
\begin{gathered}
\max _{e} U=\frac{e}{k} R^{h}+\left(1-\frac{e}{k}\right) R^{l}-\frac{e^{2}}{q k} I-(1-T) \frac{I^{2}}{p} \\
\frac{d(U)}{d e}=\frac{\Delta R I}{k}-\frac{2 e}{q k} I=0 \\
e^{c s}=\frac{q \Delta R}{2}
\end{gathered}
$$

Second, the level of investment is set by maximizing the following objective function of the private agent.

$$
\begin{gathered}
\max _{I} U=\frac{e}{k} R^{h}+\left(1-\frac{e}{k}\right) R^{l}-\frac{e^{2}}{q k} I-(1-T) \frac{I^{2}}{p} \\
\frac{d(U)}{d I}=\frac{\Delta R e}{k}+R^{l}-\frac{e^{2}}{q k}-2(1-T) \frac{I}{p}=0 \\
I^{c s}(C)=p \frac{q(\Delta R)^{2}+4 k R^{l}}{8(1-T) k}
\end{gathered}
$$

Finally, the public regulator sets the cost sharing variable anticipating what will be the optimal investment choice of the private agent:

Finally, the public regulator sets the transfer anticipating what will be the optimal investment choice of the private agent:

$$
\max _{T} W=\frac{e}{k} S^{h}+\left(1-\frac{e}{k}\right) S^{l}-(1+\lambda) T \frac{\left(I^{c S}\right)^{2}}{p}
$$




$$
\begin{aligned}
& \frac{d(W)}{d T}=\left(\frac{e}{k} \Delta S+S^{l}\right) p \frac{\left(q \Delta R^{2}+4 k R^{l}\right)}{8(1-T) k}-\frac{(1+\lambda)}{p}\left(p \frac{\left(q \Delta R^{2}+4 k R^{l}\right)}{8(1-T) k}\right)^{2} \\
& -(1+\lambda) T \frac{\left(q \Delta R^{2}+4 k R^{l}\right)}{4(1-T) k} p \frac{\left(q \Delta R^{2}+4 k R^{l}\right)}{8(1-T)^{2} k}=0 \\
& \frac{d(W)}{d T}=p \frac{\left(q \Delta R^{2}+4 k R^{l}\right)\left(q \Delta R \Delta S+2 k S^{l}\right)}{16(1-T)^{2} k^{2}}-(1+\lambda)\left(p \frac{\left(q \Delta R^{2}+4 k R^{l}\right)^{2}}{64(1-T)^{2} k^{2}}\right) \\
& -(1+\lambda) T p \frac{\left(q \Delta R^{2}+4 k R^{l}\right)^{2}}{32(1-T)^{3} k^{2}}=0 \\
& \frac{d(W)}{d T}=\left(q \Delta R^{2}+4 k R^{l}\right)\left(q \Delta R \Delta S+2 k S^{l}\right)-(1+\lambda)\left(p \frac{\left(q \Delta R^{2}+4 k R^{l}\right)^{2}}{4}\right) \\
& -(1+\lambda) T p \frac{\left(q \Delta R^{2}+4 k R^{l}\right)^{2}}{2(1-T)}=0 \\
& \frac{d(W)}{d T}=\left(q \Delta R \Delta S+2 k S^{l}\right)-(1+\lambda)\left(\frac{\left(q \Delta R^{2}+4 k R^{l}\right)}{4}\right)-(1+\lambda) T \frac{\left(q \Delta R^{2}+4 k R^{l}\right)}{2(1-T)}=0 \\
& \frac{d(W)}{d T}=4\left(q \Delta R \Delta S+2 k S^{l}\right)(1-T)-(1+\lambda)\left(q \Delta R^{2}+4 k R^{l}\right)(1-T)-2(1+\lambda) T\left(q \Delta R^{2}+4 k R^{l}\right) \\
& =0 \\
& \frac{d(W)}{d T}=T\left[4\left(q \Delta R \Delta S+2 k S^{l}\right)+(1+\lambda)\left(q \Delta R^{2}+4 k R^{l}\right)\right] \\
& =4\left(q \Delta R \Delta S+2 k S^{l}\right)+(1+\lambda)\left(q \Delta R^{2}+4 k R^{l}\right) \\
& T^{c s}=\max \left\{\frac{4\left(q \Delta R \Delta S+2 k S^{l}\right)-(1+\lambda)\left(q \Delta R^{2}+4 k R^{l}\right)}{4\left(q \Delta R \Delta S+2 k S^{l}\right)+(1+\lambda)\left(q \Delta R^{2}+4 k R^{l}\right)}, 0\right\}
\end{aligned}
$$

Then, the value of the investment at the equilibrium is:

$$
I^{c s}=\max \left\{I^{p r}, \quad \frac{p\left[q \Delta R^{2}+4 k R^{l}\right]}{16 k}+\frac{p\left[q \Delta R \Delta S+2 k S^{l}\right]}{4(1+\lambda) k}\right\}
$$




\section{Appendix E}

\section{Instructions [Translated from French to English]}

Welcome to our laboratory.

You will participate in an experiment on decision making. All subjects participating in the experiment have exactly the same instructions.

If you carefully follow the instructions, your decisions can allow you to earn an amount of money.

The amount of money that you will earn will partially depend on your decisions, partially on the decisions of the other participants, and partially on random draws.

The amount of money earned during the experiment will be paid out at the end of the experiment. At the end of the instructions, do not hesitate to ask questions.

\section{General instructions}

The experiment is made of three games.

The instruction for the first game will be directly handed out.

The instruction for the second game will be handed out after the first game.

The instruction for the third game will be handed out after the second game.

In each game you can earn money. The total amount of money earned during the experiment is given by the sum of earnings in the three games.

You will know earnings of the first two games only at the end of the experiment.

At the end of the experiment, you will be individually called to receive your earnings in cash.

First game of the experiment (GAME 1)

During this game, you are asked to make a sequence of choices. You need to choose between two options, option 'Left' and option 'Right'. These options refer to the allocation of a given amount of euros between you (Player A) and another subject in the room (Player B).

Options:

- Option Left will pay you 10 euros, and 0 euro to player B;

- Option Right will pay you and player B an equal amount of X euors. This amount is increasing as one moves from the top to the bottom of the table below.

\begin{tabular}{|c|c|c|c|}
\hline $\begin{array}{c}\text { Option Gauche : } 10 € \text { pour le joueur } A \text { et } 0 \\
\text { pour le joueur B. }\end{array}$ & Gauche & Droite & $\begin{array}{c}\text { Option Droite : X€ pour le joueur A et } \\
\text { pour le joueur B. }\end{array}$ \\
\hline$(10 €, 0 €)$ & • & 0 & $(0 €, 0 €)$ \\
\hline$(10 €, 0 €)$ & 0 & 0 & $(1 €, 1 €)$ \\
\hline$(10 €, 0 €)$ & 0 & 0 & $(2 €, 2 €)$ \\
\hline$(10 €, 0 €)$ & 0 & 0 & $(3 €, 3 €)$ \\
\hline$(10 €, 0 €)$ & 0 & 0 & $(4 €, 4 €)$ \\
\hline$(10 €, 0 €)$ & 0 & 0 & $(5 €, 5 €)$ \\
\hline$(10 €, 0 €)$ & 0 & 0 & $(6 €, 6 €)$ \\
\hline$(10 €, 0 €)$ & 0 & 0 & $(7 €, 7 €)$ \\
\hline$(10 €, 0 €)$ & 0 & 0 & $(8 €, 8 €)$ \\
\hline$(10 €, 0 €)$ & 0 & 0 & $(9 €, 9 €)$ \\
\hline$(10 €, 0 €)$ & 0 & ○ & $(10 €, 10 €)$ \\
\hline
\end{tabular}

Remark: You cannot make inconsistent decisions during this game. More precisely, if you select option Left for a certain amount X, you are assigned option Left also for all amounts lower than X. Similarly, if you select option Right for a certain amount X, you are assigned option Right also for all amounts higher than $\mathrm{X}$. The computer can modify your choices during your decision-making process 
to make your decisions coherent with the two above-mentioned principles. In the same way, the computer imposes option Left when $\mathrm{X}$ is equal to 0 Euro and option Right when $\mathrm{X}$ is equal to 10 Euro.

\section{Payment for GAME 1:}

At the end of the experiment, the computer randomly determines whether you are player A or B. If you are player A, you will randomly draw the amount $\mathrm{X}$. In the case you have chosen option Right for the drawn amount $\mathrm{X}$, thus you and player $\mathrm{B}$ will receive the same earning which is equal to the amount $X$. In the case you have chosen the option Left for the specific amount X, you will earn 10 Euro and Player B will win 0 Euro.

If you are player B, you do not have any decision to make and your earning will depend on player A's choices and on the draw of the amount X. If player A has chosen option Right for the drawn amount $\mathrm{X}$, thus you and player A will receive the same earning, which is equal to the amount $\mathrm{X}$. If player $\mathrm{A}$ have chosen the option Left, you will earn 0 Euro and player A will win 10 Euro.

The draw is performed on an individual basis during this game.

\section{Second game of the experiment (GAME 2)}

Before starting the game, the computer will ask whether you prefer blue or yellow as winning color. During this game, you are asked to make a sequence of decisions. You need to choose between two options: option 'Left' and option 'Right'.

\section{Options:}

- Option Left is a lottery. The computer will select at random a ball from an urn composed of 5 blue balls and 5 yellow balls. If the drawn ball is of the same color as your winning color, then you will get 10 Euro, otherwise you will get 0 Euro.

- Option Right will give you a certain amount X within a range from 0 to 10 Euro.

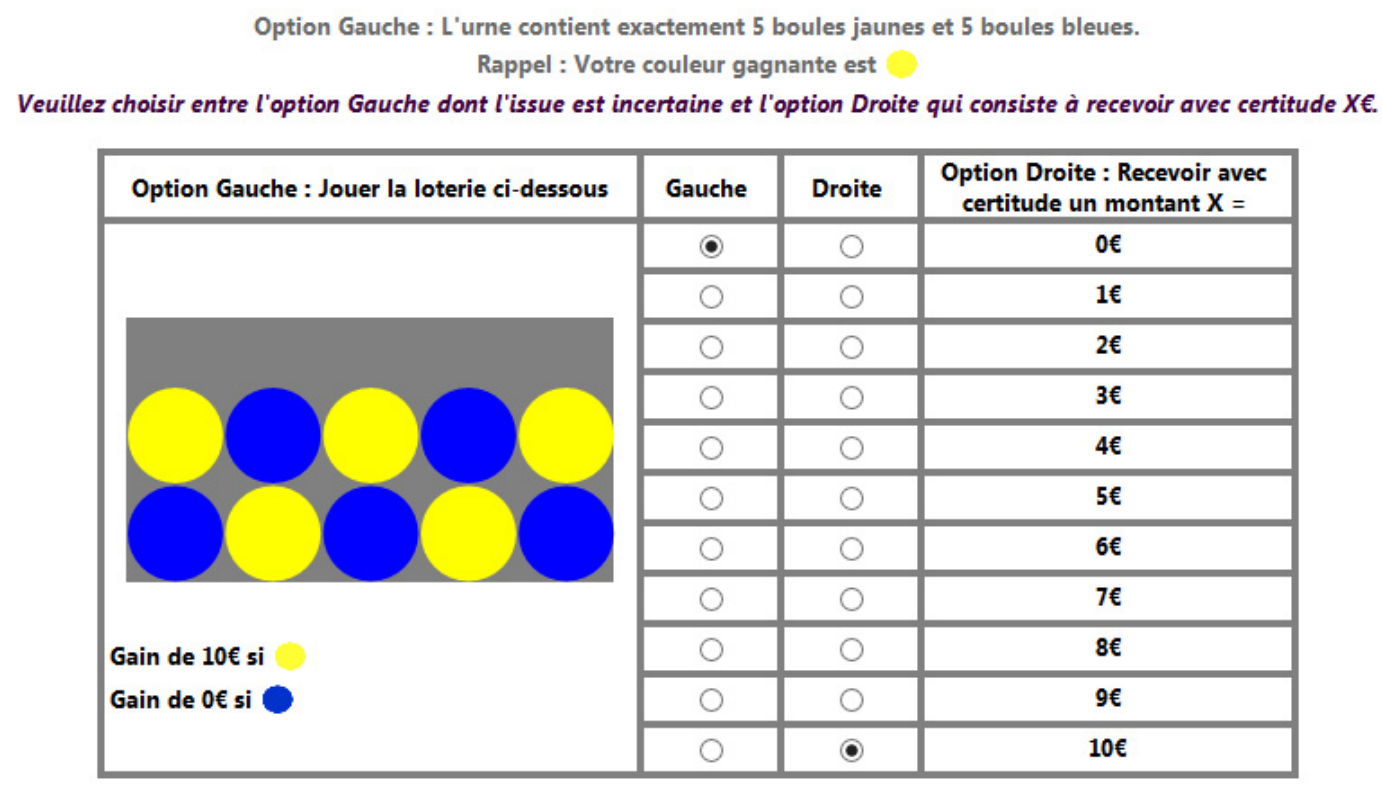

Remark: You cannot make inconsistent decisions during this game. More precisely, if you select option Left for a certain amount X, you are assigned option Left also for all amounts lower than X. Similarly, if you select option Right for a certain amount X, you are assigned option Right also for all amounts higher than $\mathrm{X}$. The computer can modify your choices during your decision-making process to make your decisions coherent with the two above-mentioned principles. In the same way, the computer imposes option Left when $\mathrm{X}$ is equal to 0 Euro and option Right when $\mathrm{X}$ is equal to 10 Euro. 
Payment for GAME 2:

First, the computer will randomly choose an amount $\mathrm{X}$ (one of the lines will be selected).

For this amount X:

- In the case you chose option Left, a ball will be drawn from the urn. If the ball is of the same color as your winning color, you will earn 10 Euro, otherwise you will win 0 Euro.

- In the case you chose option Right, you will earn for sure the amount X Euro.

The draw is performed on an individual basis during this game.

\section{Appendix F}

\section{Third game of the experiment (GAME 3)}

\section{General Instructions}

You are randomly designed as a player $\mathrm{X}$ or $\mathrm{Y}$ at the beginning of the game and you keep your role as $\mathrm{X}$ or $\mathrm{Y}$ all along the twelve periods of the game. You are in total 24 participants in this game. 12 individuals will be designed as players $\mathrm{X}$ and 12 individuals will be designed as players $\mathrm{Y}$. At the beginning of each of the 12 periods, pairs of participants are randomly created. Each pair is constituted with one $\mathrm{X}$ and one $\mathrm{Y}$. If you are designed as a player $\mathrm{X}$, you will be in relation with a $\mathrm{Y}$ player. Inversely, if you are designed as Y player, you will be in relation with a player X. You will not know the identity of the other player. The participant you will meet at each period is randomly designed and you will never meet twice the same player all along the 12 periods.

\section{Decisions and gains for players $\mathrm{X}$ and $\mathrm{Y}$}

All along the 12 periods, the gains of the two players $X$ and $Y$ will depend on

$\rightarrow$ a level of investment $I$,

$\rightarrow$ the result of a random drawing of a ball from an urn with 8 black and white balls,

$\rightarrow$ the value of a cost-sharing coefficient $T$.

The investment I will give an identical income to the 2 players and the drawn ball will determine the level of the income. Investment I will generate a cost of investment for player $Y$ and the value of $T$ will determine the share of $Y$ 's investment cost that will be paid by player X.

- Time-line :

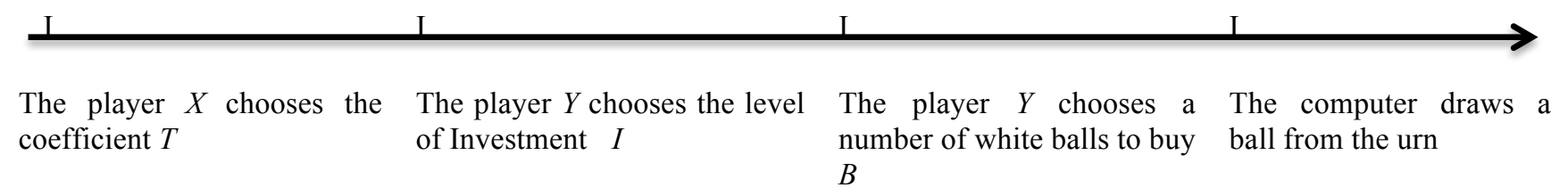

- Decision of player $X$ :

At each period player $X$ must decide if he wants to share or not a part of the $Y$ 's investment cost, by choosing the value of the coefficient $T$. The coefficient $T$ can take four possible values: $0 \%, 20 \%$, $50 \%$, or $80 \%$ and the cost of $X$ is finally equal to: $\frac{T * I^{2}}{4}$. Notice that this cost increases with $I$ and that $X$ can decide to share nothing by choosing $T$ equal to 0 . Player $Y$ will know the value of $T$ before choosing the level of I and the number of white balls $B$ to buy. 
- Decisions of player $Y$ :

At each period player $Y$ must take sequentially two types of decisions: the level of investment $I$, and the level of white balls $B$ to buy from an urn made of 8 balls.

The player $Y$ 's investment $I$ can be any integer between 0 and 8 , it will generate for player $Y$ an investment cost equal to: $\frac{(1-T) * I^{2}}{4}$, and it gives an identical income to players $X$ and $Y$. The amount of this income will depend on the color of the ball that will be drawn. Notice that this $Y$ 's investment cost will be equal to $\frac{I^{2}}{4}$ if the player $X$ decide not to contribute to the $Y$ 's investment cost, by choosing a $T$ equal to 0 .

Notice that both the cost of investment and the final income are increasing with the level of investment $I$. However, the investment cost is decreasing with the coefficient $T$.

The number of white balls B that are bought can take 4 values: $0,2,4$ or 6 . According to this value, the urn will be compound with either 0 white ball and 8 black ones, or 2 white balls and 6 black ones, or 4 white balls and 4 black ones, or 6 white balls and 2 black ones. The probability to draw a white ball is then equal to $\frac{\mathrm{B}}{8}$.

The cost to purchase $B$ balls for player $Y$ is equal to: $\frac{B^{2} * I}{16}$

Notice that this purchase cost is increasing with the number of white balls B and the level of investment I.

\section{Gains of players $X$ and $Y$ :}

The level $I$, the number $B$ bought by player $Y$ as well as the value of $T$ will influence the gains for the 2 players $X$ and $Y$ for the current period, together with the color of the ball that will be drawn.

- If the ball drawn by the computer at the end of the period is white :

$$
\begin{array}{ll}
\text { The gain of } X \text { is equal to: } & \mathbf{5} * I-\left(\frac{T * I^{2}}{4}\right) \\
\text { The gain of } Y \text { is equal to: } & \mathbf{5} * I-\left(\frac{(1-T) * I^{2}}{4}\right)-\left(\frac{B^{2} * I}{16}\right)
\end{array}
$$

- If the ball drawn by the computer at the end of the period is black:

$$
\begin{array}{ll}
\text { The gain of } X \text { is equal to: } & 1 * I-\left(\frac{T * I^{2}}{4}\right) \\
\text { The gain of } Y \text { is equal to: } & 1 * I-\left(\frac{(1-T) * I^{2}}{4}\right)-\left(\frac{B^{2} * I}{16}\right)
\end{array}
$$

$\mathbf{5} * \boldsymbol{I}$ being the income that is generated by investment $I$ for the 2 players if the drawn ball is white, while the income is equal to $1 * \boldsymbol{I}$ if the drawn ball is black.

$\left(\frac{T * I^{2}}{4}\right)$ is the level of $Y$ 's investment cost that is paid by the player $X$, this level is independent on the result of the random drawing.

Notice that for a coefficient T different from 0, the higher the Y's investment I will be, the higher will be the X's shared cost. This cost is also increasing with the value of the coefficient $T$.

Before taking his decision, player $X$, using the table below, will be able to simulate all possible gains by selecting different values of $T$ for all possible combinations of $I$ and $B$ chosen by player Y. Likewise, the player $Y$ before taking his decisions will have at one's disposal a table that will give him $X$ 's and $Y$ 's gains for all possible combinations of $I$ and $B$, and given the coefficient $T$ that has been chosen by player $X$.

For example, the table below shows for the player $X$ all possible gains of $\mathrm{X}$ and $Y$ depending on the coefficient $T$. 


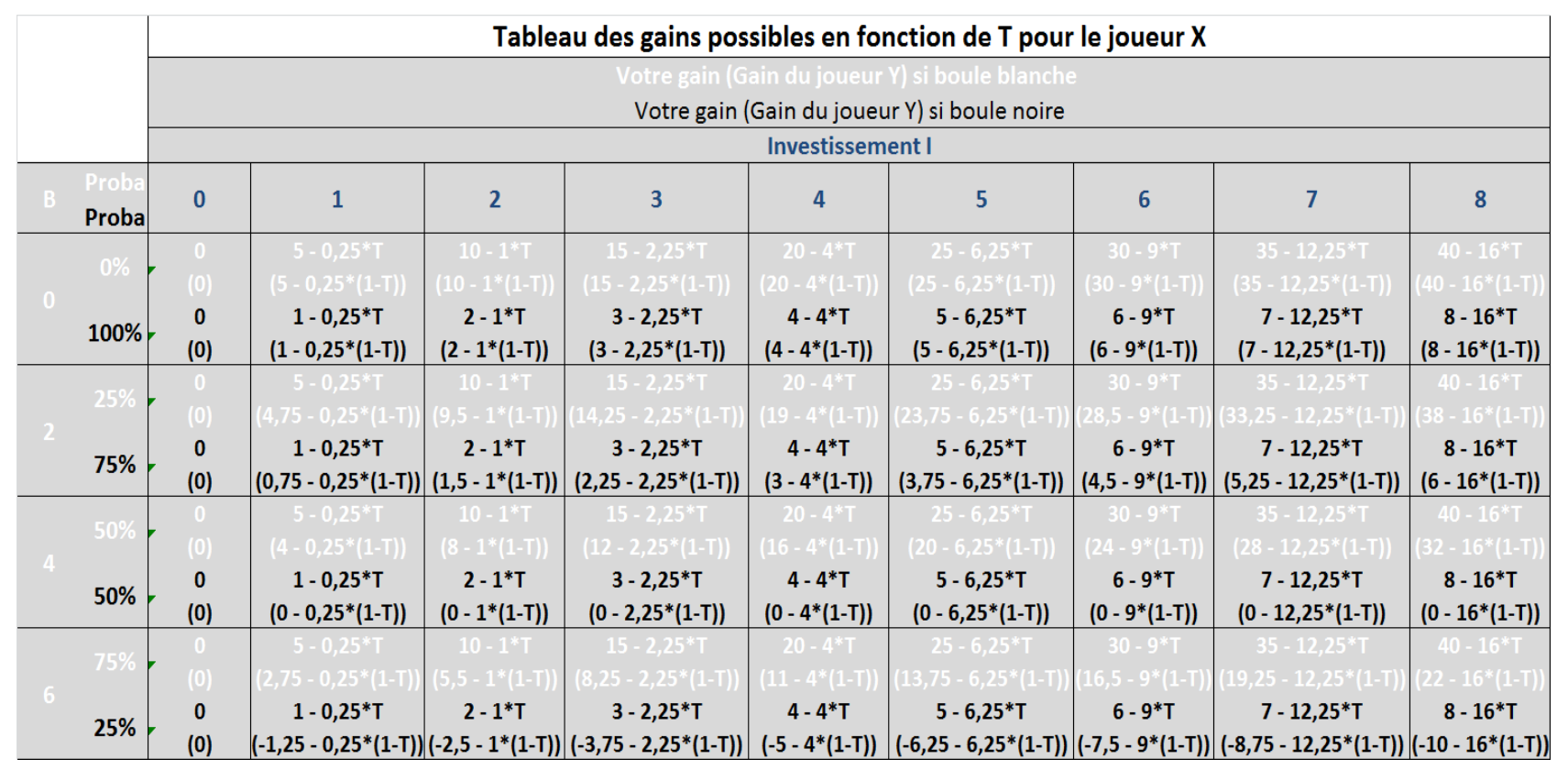

You have to read the table in the following way:

Columns represent the levels of investment of the player $Y$ according to an ascending order; lines represent the number of white balls that $Y$ can buy according to an ascending order.

For each given $T, I$ and $B$, the table gives (in white) your gain followed by your partner's one (into parentheses) if the drawn ball is white. The column 'Proba' precises (in white) the probability to obtain these gains according to the number of white balls that are bought.

For each given $T, I$ and $B$, the table gives (in black) your gain followed by your partner's one (into parentheses) if the drawn ball is black. The column 'Proba' precises (in black) the probability to obtain these gains.

In this example, $X$ 's gains are indicated first, followed by $Y$ 's gains (into parentheses).

Notice that if I is null, gains for the two players will be null whatever the decisions that are taken by the 2 players and whatever the result of the random drawing. However, for any I non null and given $B$ and $T$, gains are always higher for the 2 players if the drawn ball is white than if it is black.

For instance, if the player $X$ chooses a $T$ equal to $80 \%$, and the player $Y$ chooses an $I$ equals to 5 and a $B$ equals to 6 , then gains of $X$ and $Y$ will be respectively equal to $20\left(=25-6,25^{*} 0,8\right)$ and $12,5(=$ $13,75-6,25 * 0,2)$ with a probability of $75 \%$ (white ball), or to $0(=5-6,25 * 0,8)$ and $-7,5(=-6,25-$ $6,25 * 0,2)$ with a probability of $25 \%$ (black ball).

Similarly, if player $X$ chooses a $T$ equal to $50 \%$, and the player $Y$ chooses an $I$ equals to 6 and a $B$ equals to 4 , then gains for $X$ and $Y$ will be respectively equal to $25,5(=30-9 * 0,5)$ and $19,5(=24$ $9 * 0,5)$ with a probability of $50 \%$ (white ball) or to $1,5(=6-9 * 0,5))$ and $-4,5(=0-9 * 0,5)$ with a probability of $50 \%$ (black ball).

\section{Summary of the chronology within each period}

At each period, player $X$ chooses a cost-sharing coefficient $T$ to share (or not) a part of the investment cost of player $Y$. Then, player $Y$ sequentially chooses a level of investment $I$, and the number of white balls $B$ to buy, knowing the value of $T$ chosen by $X$.

$T$ can take four possible values : $0 \%, 20 \%, 50 \%$, ou $80 \%, I$ can be any integer number between 0 and 8 , and $B$ can be any even number between 0 et 6 .

Notice: After the choice of T, X must predict the level I and the number of white balls $B$ that $Y$ will choose for the given value of $T$. These predictions will not have any influence nor on the Y's gains nor on his own gains.

As soon as $Y$ has taken his decisions, the computer will draw a ball from an urn compound with $B$ white ball(s) and $8-B$ black ball(s). The color of this ball will determine the gains of the 2 players, that will be announced to them. If the color of the drawn ball is white, then the 2 players will get the 
highest gains depending on the coefficient $T$ chosen by $X$ and on $I$ and $B$ chosen by $Y$. On the contrary, they will get the lowest gains is the color of the drawn ball will be black. Notice that, at the end of the period, player $X$ will know only the $Y$ 's investment $I$ but not the number of white balls $B$ that he bought.

The subsequent period will start as soon as all participants will have taken their decisions. Before taking your decisions, you will get access to the history of the game. It will remind you, for each past period, all your decisions, results of the random drawings, and your past gains.

Before the beginning of this game, you will have to answer some questions to verify your level of understandings on instructions.

For each of the 12 periods, your gains will be expressed in points. At the end of the game, your total points will be converted into $€$ ( $1 €$ for 10 points). 